\title{
Polymer Composites in Construction: An Overview
}

\author{
Ayman S Mosallam*, Alemdar Bayraktar ${ }^{2}$, Mohamed Elmikawi $^{3}$, Salim Pul' and Suleyman Adanur ${ }^{2}$ \\ ${ }^{1}$ Department of Civil \& Environmental Engineering, University of California, USA \\ ${ }^{2}$ Department of Civil Engineering, Karadeniz Technical University, Turkey \\ ${ }^{3}$ Department of Structural Engineering, Ain Shams University, Egypt
}

Received: November 23, 2013; Accepted: January 28, 2014; Published: February 11, 2014

*Corresponding author: Ayman S Mosallam, Department of Civil \& Environmental Engineering, of California, Irvine (UCI), Irvine, California 926972175, USA, Tel: +1-949-824-3369; Fax:+1-949-824-2117; E-mail: mosallam@uci.edu

\begin{abstract}
This paper provides an overview on some of the latest advances in the applications of fiber reinforced polymeric (FRP) composites in construction. The paper focuses on three main inter related review areas, namely; (i) Repair and rehabilitation of concrete, steel, masonry and wood structures using composites, and (ii) All-composite structural applications that includes buildings and bridges, and (iii) Latest development on design codes, materials specifications, design manuals and national and international standards for composites used in civil infrastructure applications.
\end{abstract}

Keywords: Construction; Highway bridges; FRP composites; Rehabilitation; Repair; Safety; Impact; Fatigue; Reinforced concrete; Beam-column joints; Wood repair; Steel repair; Masonry repair; concrete columns; Bridge collision; LDPE composites; Codes; Standards

\section{Introduction}

In a recent report, the Federal Highway Administration (FHWA) estimated that to eliminate the nation's bridge deficient backlog by 2028 , we would need to invest $\$ 20.5$ billion annually, while only $\$ 12.8$ billion is being spent currently. To make this difference, federal, state, and local governments would need to increase their bridge investments by about $\$ 8$ billion annually to address the identified $\$ 76$ billion in need for deficient bridges across the United States. It was also reported that traffic congestion costs the US economy $\$ 67.5$ billion annually in lost productivity and wasted fuel. This costly traffic congestion is blamed, to a major extent, on the existence of this increasing large numbers of structurally-deficient and functionally-obsolete bridge. Both weight and speed restrictions are required in the case of structurally-deficient bridges. Functionally-obsolete bridges are those designed according to older codes and load requirements and are currently not capable of safely accommodate increasing traffic volumes, vehicle sizes and weights. For this reason, there is an urgent need for developing rapid and cost-effective methods to repair structurally-deficient bridges and to upgrade the functionally-obsolete bridges. In 2013 Report Card prepared by the American Society of Civil Engineers (ASCE) stated that “..Over two hundred million trips are taken daily across deficient bridges in the nation's 102 largest metropolitan regions. In total, one in nine of the nation's bridges are rated as structurally deficient, while the average age of the nation's 607,380 bridges is currently 42 years..." [1].

Strengthening and repairing existing highway bridges as well as other constructed facilities are considered to be major challenges facing structural engineers worldwide. In the past few years, a number of innovative methodologies for upgrading the capacity of steel, concrete and timber bridges and structures have been developed. However, the majority of these innovative methods are still in the development stage and applications of such technologies are still considered as demonstration projects. This delay in moving innovative bridge developments from the laboratory to field application is attributed to several factors including liabilities-related concerns and conservatism on the part of department of transportation (DOT) decision makers, limitation of resources, lack of awareness of the technology and its positive impact on bridge performance and most important the absence of a standard concentrated approach for rolling out innovations. In order to speed the technology transfer process and to increase the confident level among engineers on the performance of such new technologies, assessment tools such as structural health monitoring and diagnostic/prognostic systems are needed. These techniques will provide structural engineers with updated information on the performance of repaired and rehabilitated structural systems.

In this paper, selected successful applications of composites are described. In addition a review of available standards, acceptance criteria and design guides are also presented.

\section{Repair \& rehabilitation of reinforced concrete members using FRP composites}

Repair and rehabilitation of reinforced concrete (RC) columns was the first successful applications of FRP composites that were initiated in early 1990 (Figure 1). This application was extended other applications including RC beams, floor slabs and bridge decks, beam-column joints, pipes, tanks, shear walls and other structural members as shown in Figure 2. A comprehensive coverage for different repair and rehabilitation applications of composites is reported by Mosallam AS [2]. 
An effective multi-criteria systematic approach based on the analytical hierarchy process (AHP) was developed to assist decision-makers in evaluating the use of advanced materials by El-Mikawi M \& Mosallam AS [3]. The AHP methodology provides decision-makers with the means to evaluate the use of various structural materials based on specific applications, optimizing the use of limited resources. One of the key elements of the model is the ability to handle complex problems and alternatives with multiple objectives.

\section{Emergency seismic repair of Reinforced Concrete Bridge shear columns}

During an earthquake of large magnitude, reinforced concrete columns may be severely damaged limiting the functional capacity of structures including highway bridges. It is essential that damaged columns be temporarily repaired to ensure continuous functionality and safety of essential structures. One of the promising techniques is the use of FRP composite jackets to regain its lateral capacity and to enhance its ductility. The successful strengthening system must be pre-designed and be readily available for fast implementation to mitigate further damage that may be caused by aftershocks.

In a pilot study conducted at UCI to develop and evaluate a rapid emergency repair technique for RC bridge columns. In this study "as-built" column was subjected to full-reversal cyclic shear loads were tested to failure. The unstrengthened column was severely damaged as shown in Figure 3. A rapid repair system comprised of a combination of fast-setting epoxy mortar and four plies of unidirectional carbon/epoxy composites jacket was developed and applied to the damage specimen. The strengthened column was retested under identical lateral cyclic loading (Figure 3). The repaired column showed excellent performance as it developed flexural behavior with a ductility of 4.0 as shown in the hysteresis loops in Figure 4. This clearly demonstrates the effectiveness of such a scheme of repair that can be used to provide fast emergency repair of bridge columns, thereby reducing the traffic impacts due to bridge closure. Simple,

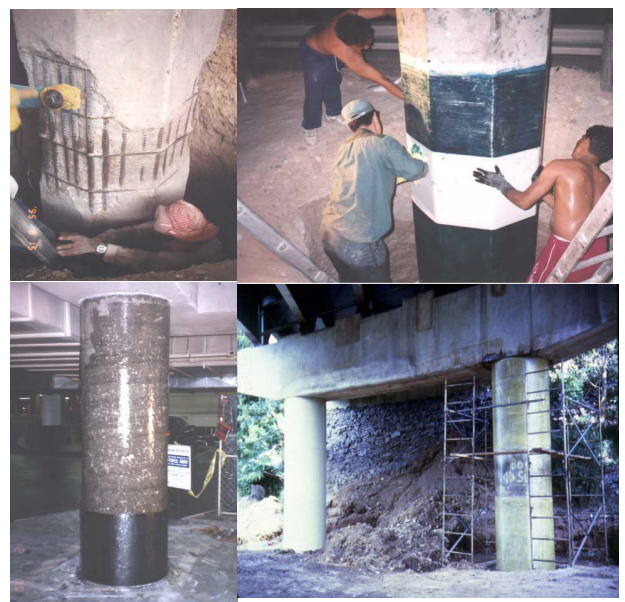

Figure 1: Repair and rehabilitation of corroded bridge \& buildings RC columns with FRP composites.

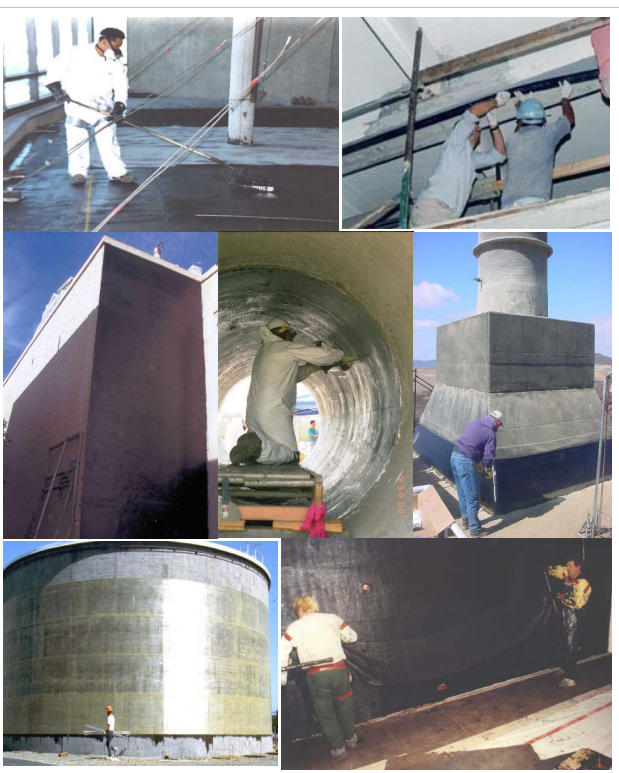

Figure 2: Examples of strengthening applications of FRP composites. a. Floor beams; b. Floor slabs; c. Masonry walls; d. Pipes; e. Foundations; f. Tanks; g. RC Shear walls
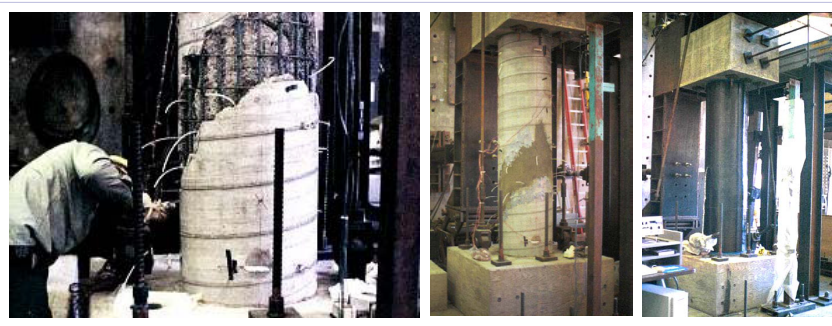

Figure 3: Full-scale cyclic tests of as-built and FRP-repaired RC columns.

yet effective semi-empirical models to predict the behavior of RC columns with different geometries (e.g. rectangular, square, circular, hexagonal, etc.) that are strengthened with both E-glass/ epoxy and carbon/epoxy jackets was developed by Youssef MN, et al. [4] that was verified using the experimental results of over 100 full-scale tests as well as available test results in open literature.

\section{Seismic repair and retrofit of reinforced concrete beam-column joints}

Lack of joint confinement in the per-1970's construction has resulted in weakened link between the column and the beam and collapse of the whole structure. The majority of past published research work has focused on the repair and retrofit of the beamcolumn exterior joints using either conventional materials or off-the-shelf polymeric composites. For example, a pioneering study introducing the use of composites for strengthening beamcolumn joints was reported by Mosallam AS [5]. Liu C [6] studied the seismic behavior of beam-column joint assemblies reinforced with steel fibers. Tsonos A [7] studied the effect of CFRP jackets on retrofitting beam-column subassemblies. Supaviriyakit T \& Pimanmas A [8] conducted a study to compare the performance 

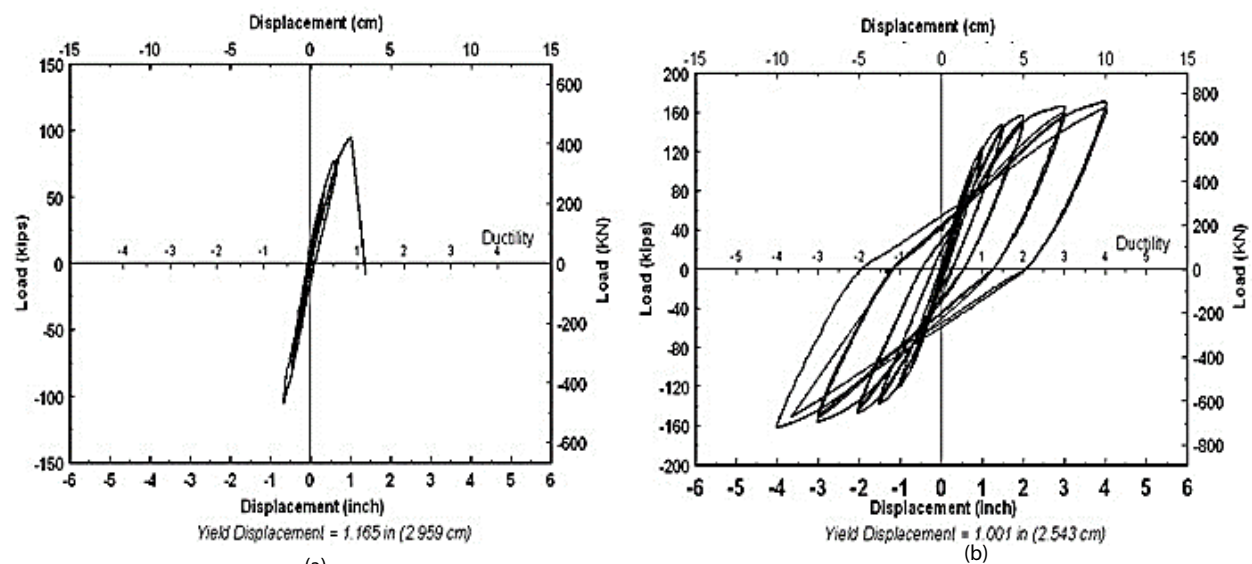

(a)

Displacement $(\mathrm{mm})$

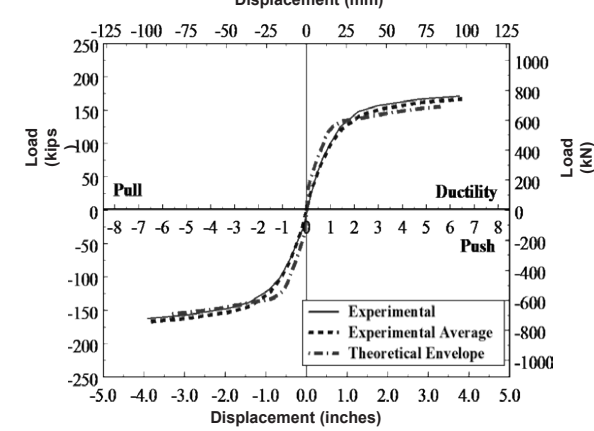

(c)

Figure 4: Comparison between hysteresis loops of:

a. As-build column

b. FRP-repaired column

c. Comparison between load-displacement envelopes for repaired column

of a substandard beam-column joint with and without initial bond between beam longitudinal bars and concrete in the joint core. Pantelides C, et al. [9] conducted a research program for seismic rehabilitation of $\mathrm{RC}$ frame interior beam-column joints with externally applied CFRP composite laminates. Mosallam AS [10] conducted a research study on structural upgrade of reinforced concrete column-tie beam assembly using FRP composites.

An innovative externally strengthening technique for reinforcing interior RC beam-column joints developed by the author through the use of a hybrid High Performance Mortar (HPM) and CFRP laminates. The hybrid HPM/CFRP composite connectors are attached to both column and beams sides using both high-strength bolts and high-strength epoxy adhesives (Figure 5). In addition, multidirectional E-glass/epoxy and carbon/epoxy composite laminates were designed for this purpose. In order to verify the effectiveness of this strengthening system, a comprehensive full-scale evaluation program was conducted. Test results indicated that a significant enhancement in the joint shear strength was achieved. The retrofitted beamcolumn specimen strengthened with high-strength carbon/ epoxy composite laminates showed an improvement in its shear strength capacity by 1.34 times as compared to the control deficient specimen beam-column specimen. The experimental results indicated also that the use of high-modulus carbon/epoxy composites in the focused deficiency application of this thesis was not very satisfactory. For example, ductility of the high-modulus/ epoxy retrofitted specimen was $36 \%$ lower than as compared to the high-strength carbon/epoxy retrofitted specimen. The use of HPM/CFRP technique for retrofitting joint specimen with rebar bond slippage was very successful. This innovative technique improved the shear strength of the joint 2.5 times the control deficient specimen. The use of advanced composite connector has prevented brittle shear failure inside the joint region and allowed a plastic hinge to develop away from the column face. The energy dissipation by the retrofitted specimen was 4.6 times the control specimen with discontinuous reinforcement rebars.

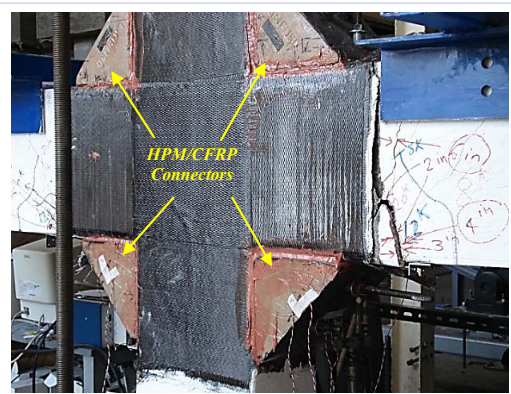

Figure 5: HPM/CFRP hybrid connector for strengthening of beam-column RC joints. 
Figure 6 shows the typical test setup for retrofitted beam-column joints. The load-displacement for shear deficient control and retrofitted specimens is presented in Figure 7.

\section{Seismic repair and retrofit of reinforced concrete shear walls with and without openings}

Remodeling of existing structures can sometimes include partial destruction of the structural members of a building as shear walls (i.e. addition of window and door openings, ducts and stairwells). In these scenarios, such buildings with new openings must be retrofitted in order to restore the seismic capacity of the structural member. Conventional retrofit techniques include epoxy injection repair, concrete jacketing, steel jacketing, and addition of external steel. Some of the attractive features of FRP composites include high strength-to-weight ratios (specific strength), higher corrosion resistance and ease of application. The majority of published research focused on the retrofit of solid shear walls [11-13]. However, there are very few studies that involved evaluation of FRP retrofit of shear walls with openings $[14,15]$.

Recently, a comprehensive research program was initiated at UCI to evaluate the effectiveness of the FRP retrofit system in restoring the loss of capacity due to the addition of the openings. The results indicated the innovative reinforcement systems designed specifically to upgrade the performance of the walls after the introduction of the openings that were not included in the original wall design performed in a satisfactory manner and were able to restore the capacities of the retrofitted walls to more than or equal to the average capacity of the original solid wall without openings. Geometrical and reinforcement details for the wall specimens evaluated in this study are described in Figure 8. The failure modes of as-built and retrofitted wall with opening specimens are shown in Figure 9. A comparison of loaddisplacement envelopes of all wall specimens is shown in Figure 10. As shown in this figure, ductility of the retrofitted wall with door opening was 3.33 as compared to 5 for the control (as-built) wall with door opening due to the localized severe debonding failure of the retrofitted wall at the connection between the

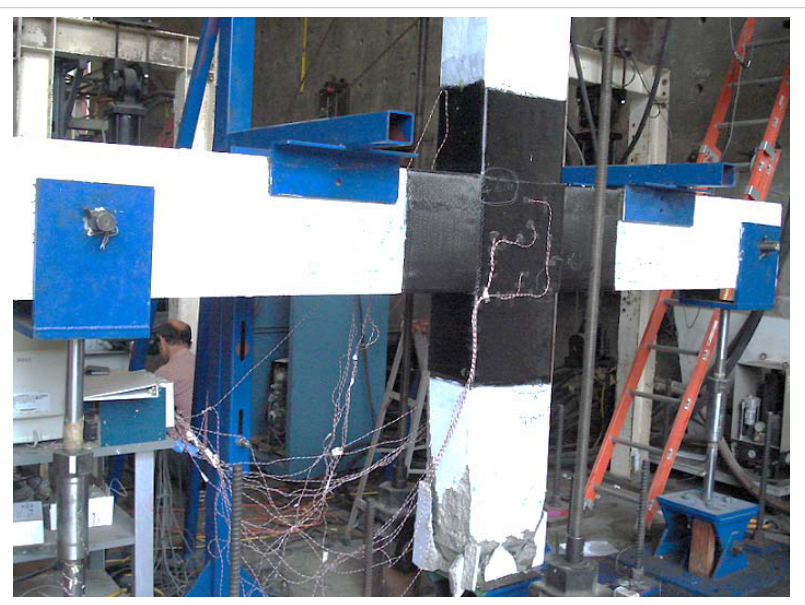

Figure 6: Typical test setup for retrofitted beam-column joints.

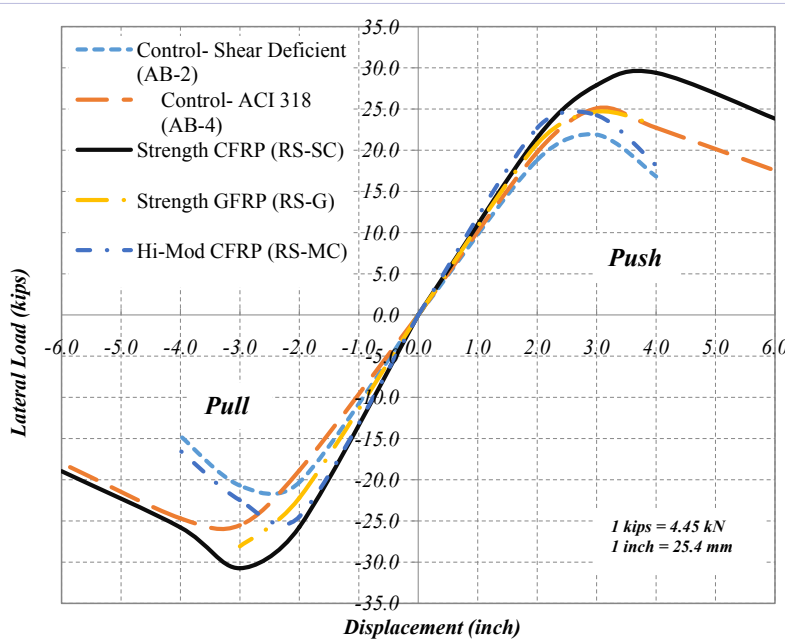

Figure 7: Load-displacement for shear deficient control and retrofitted specimens.

top spandrel and the narrow wall pier. In addition, the average ultimate load of the retrofitted wall with window opening was 1.32 times the average ultimate load of the control wall with window opening. For the retrofitted wall with door opening, the average peak load was 1.25 times the average peak load of the control wall with door opening.

\section{Flexural upgrade of reinforced concrete slabs with a hybrid HPM/CFRP}

Few decades ago, steel plates have been used to enhance flexural strength of RC floor slabs and bridge decks by externally bonded fiber reinforced polymer (FRP) composite systems have been accepted by the construction industry. Several research studies have confirmed the effectiveness of this retrofit protocol for both reinforced and unreinforced concrete slabs subjected to both static and blast loads [16,17]. Although composites can resist compressive stresses, for rehabilitation applications, it is not recommended [18], 2008). For this reason, externally bonded FRP system is preferably used to strengthen concrete members subjected to tensile stresses. Conventionally, composite laminates are installed at the top and the underside of floor slabs or bridge decks to enhance both negative and positive moment capacities (Figure 11).

While the FRP installation at the top of floor slabs or bridge decks has not met many difficulties, in most cases there are many obstacles to access the underside of the slab such as suppression system, electrical wiring and ventilation ducts. This also applies to retrofitting bridge over passes where traffic interruption in the road below is unavoidable as well bridges over waterways where the application of retrofit systems requires special shoring and special application procedures that are expensive and cumbersome in most cases. Therefore, it might be difficult to achieve the well prepared concrete surface for the FRP application at the underside of the slab or might not have access at all for logistic reasons. Moreover, additional anchoring or equipment might be necessary to hold FRP laminates during the 


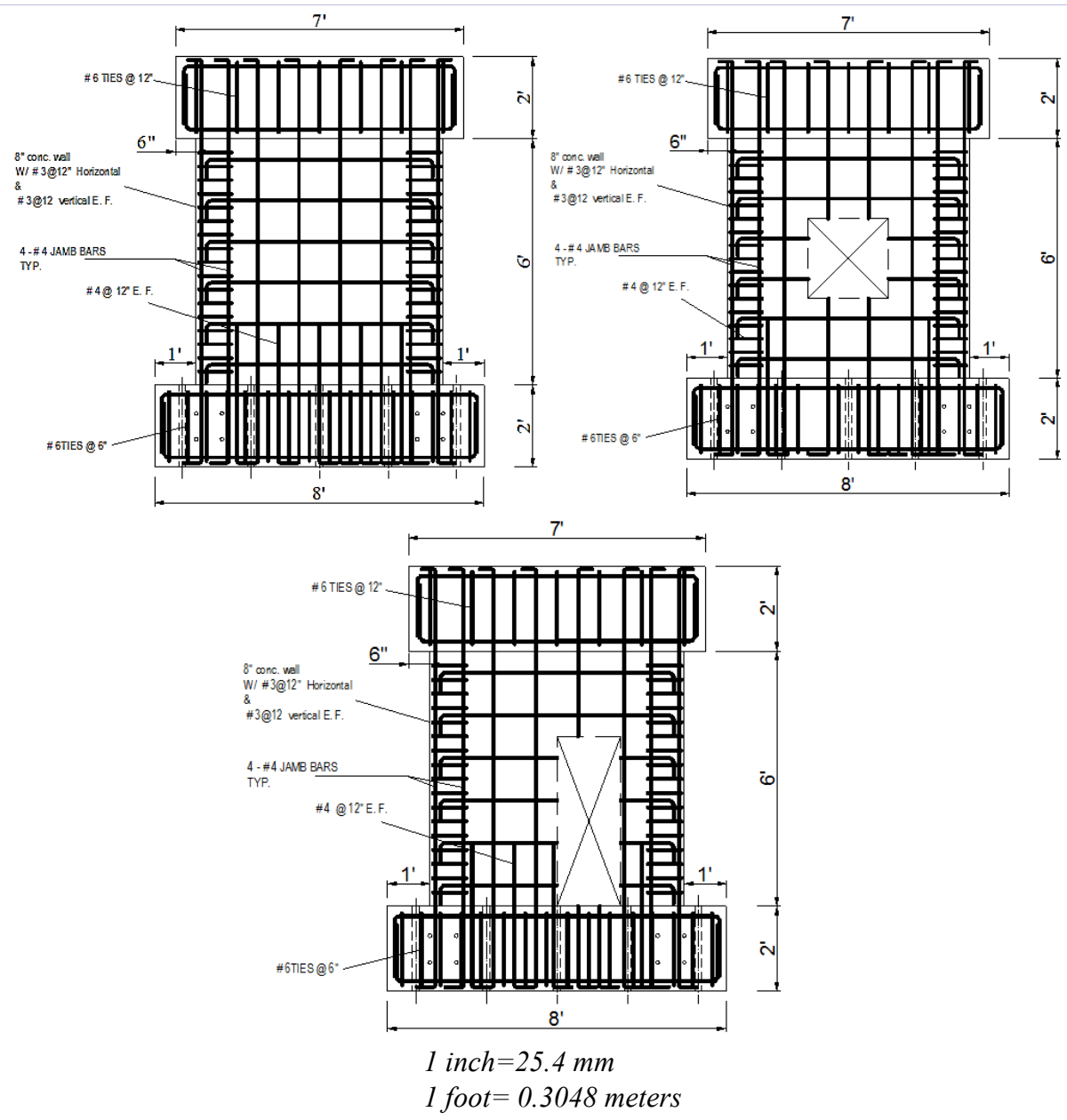

Figure 8: Wall specimens details.

a. Solid wall specimen

b. Wall specimens with a window opening

c. Wall specimens with a door opening

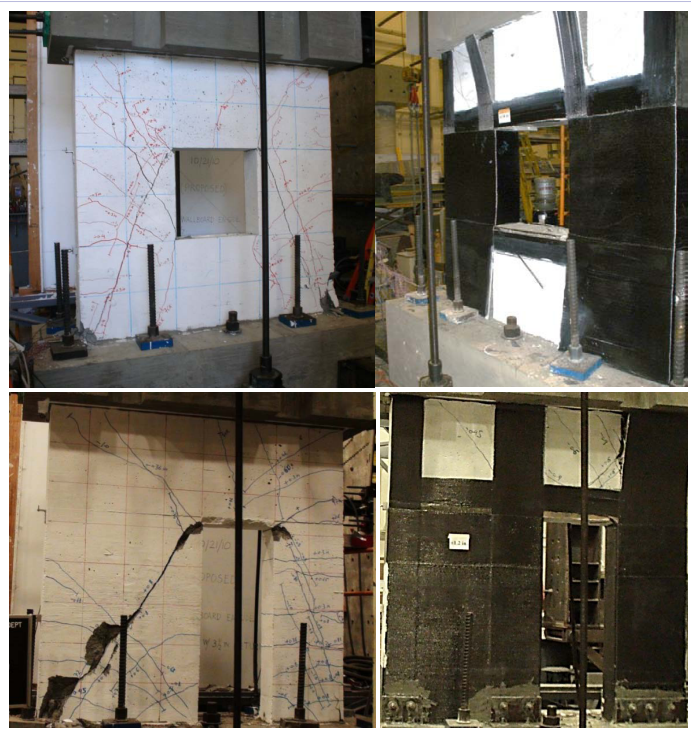

Figure 9: Failure modes of as-built and retrofitted wall with opening specimens. 
initial curing of an adhesive, which makes it further difficult to apply the FRP to the underside of slab or bridge deck.

Recently, a pilot project was initiated to develop an innovative hybrid composite system is proposed combining a high performance mortar (HPM) with carbon fiber reinforced polymer (CFRP) in the presence of adequate shear connectors. By integrating these two materials, the ability of the proposed system to increase the moment carrying capacity of RCs labs or bridge decks is demonstrated $[19,20]$. The proposed system can be installed on the top of the RC slabs or deck to enhance the positive moment capacity (Figures11 \& 12). A one-way slab with two continuous spans of $1219 \mathrm{~mm}$ wide and $2438 \mathrm{~mm}$ long is considered to examine the proposed system ability to enhance the moment capacity of the slab. Three identical one-way slabs were constructed and the proposed retrofit system is installed to

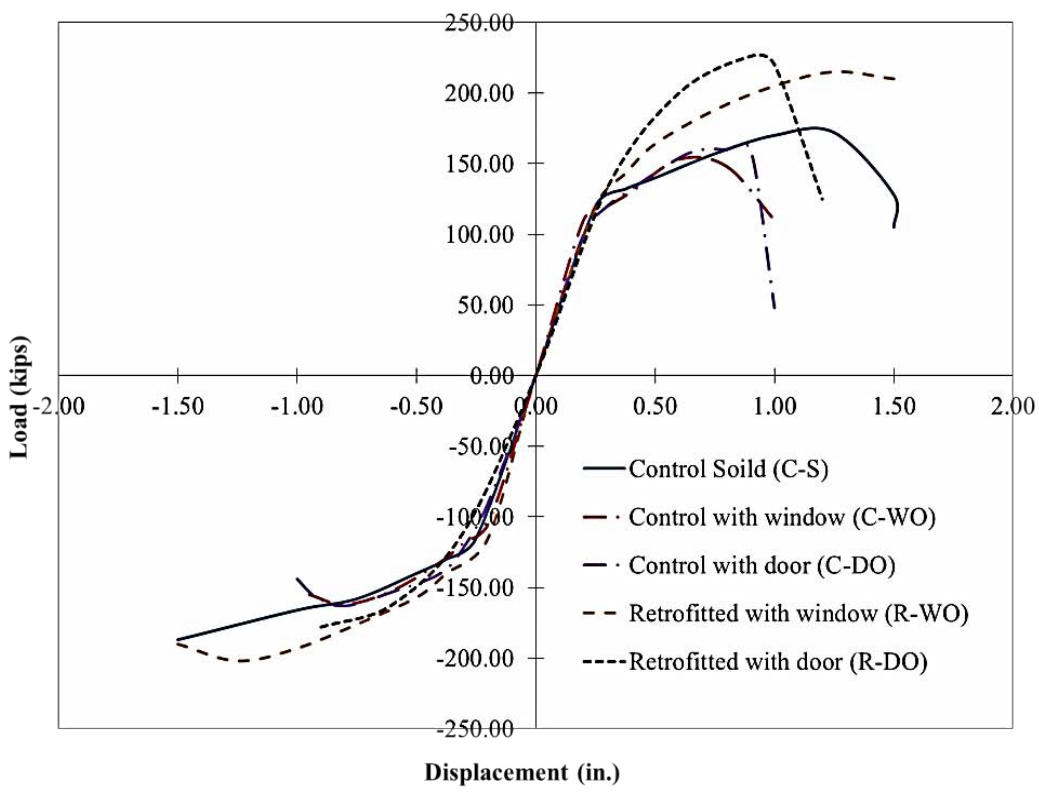

Figure 10: Comparison of load-displacement envelopes of all wall specimens.

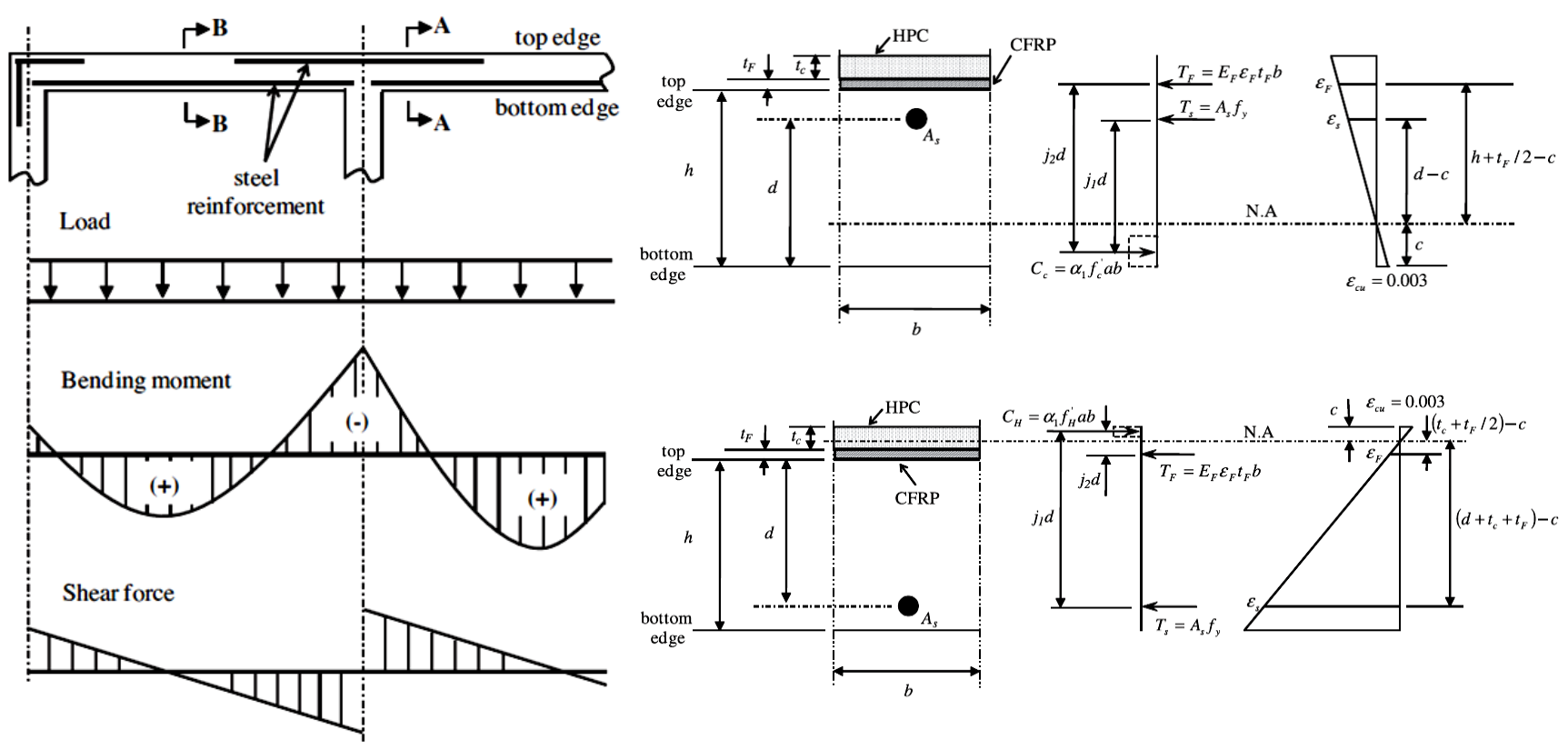

Figure 11: HPM/CFRP retrofitting mechanism for a section subjected to positive and negative bending moments.

a. Load distribution for a one-way RC slab and corresponding bending moment and shear force diagrams

b. Retrofitting mechanism for a section subjected to negative bending moment (section A-A)

c. Retrofitting mechanism for a section subjected to positive bending moment (section B-B) 
two of the slabs. Two types of HPC with compressive strength of 69 and $97 \mathrm{MPa}$ were examined. Full-scale experimental results indicated that the proposed system can increase the ultimate load capacity and ductility of the retrofitted RC slabs by about164\% and $122 \%$, respectively, as compared with the original "as-built" capacities with easy installation. Based on the verification test results, the system was approved by the City of Los Angeles, California and was adopted for use for a commercial high-rise moment frame building in Los Angeles, California (Figure 12).

\section{Collision protection system for reinforced concrete bridge girders}

One of common damages in existing highway bridges is the localized damage at the bottom corners or edges of the reinforced concrete beams or box girders induced by an impact of trucks exceeding the allowable height clearance of the bridges. Due to collision impact of the trucks, the bottom or outer layers of concrete girders are usually peeled off (Figure 13-a) so that the steel reinforcements are exposed to the surrounding environment and subjected to corrosion. This issue is also related to protection of reinforced concrete bridge superstructures and piers subjected to potential impact by barges and ships (Figure 13-b). A collision protection or scarifying system is in pressing need, and it can protect the concrete girders and piers from such impact damage and thus ensure the integrity of the bridge structures.

Functionally-degraded sandwich system for over-height collision protection of highway bridges: Mosallam AS (2004) developed an innovative functionally-degraded sandwich
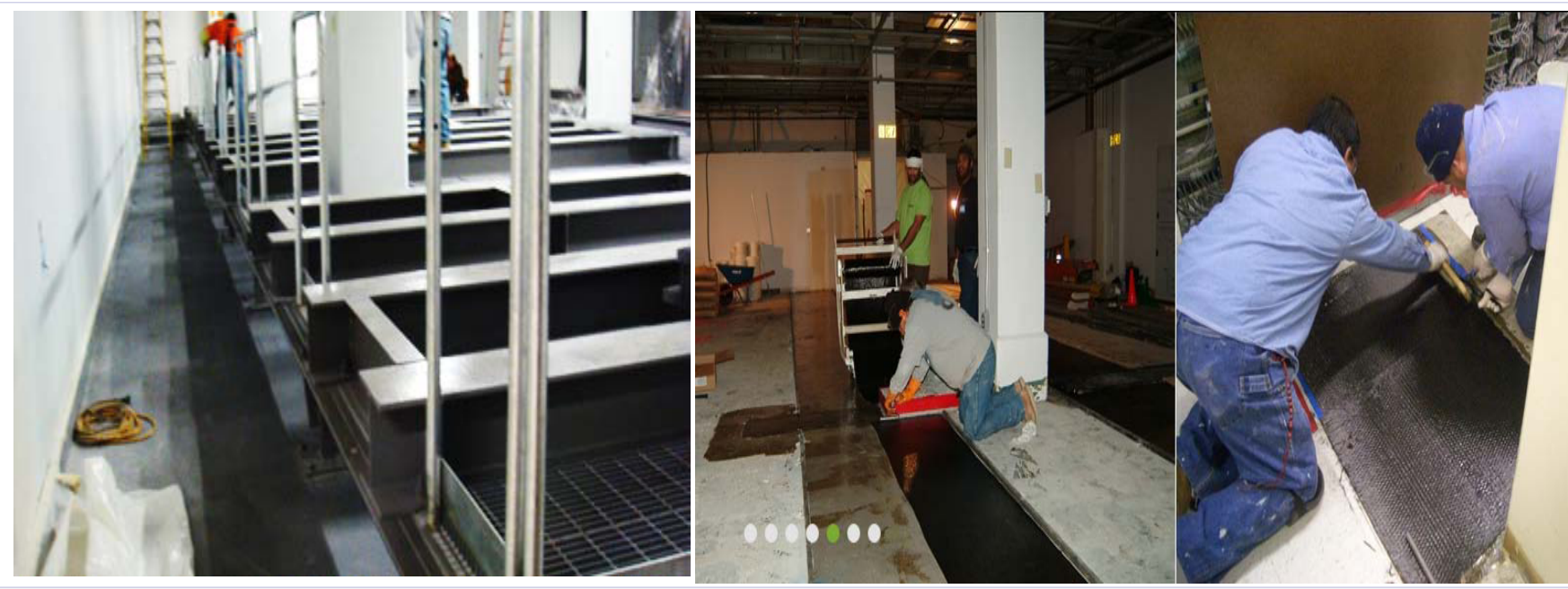

Figure 12: Field application of the HPM/CFRP system for flexural upgrade of floor slabs.
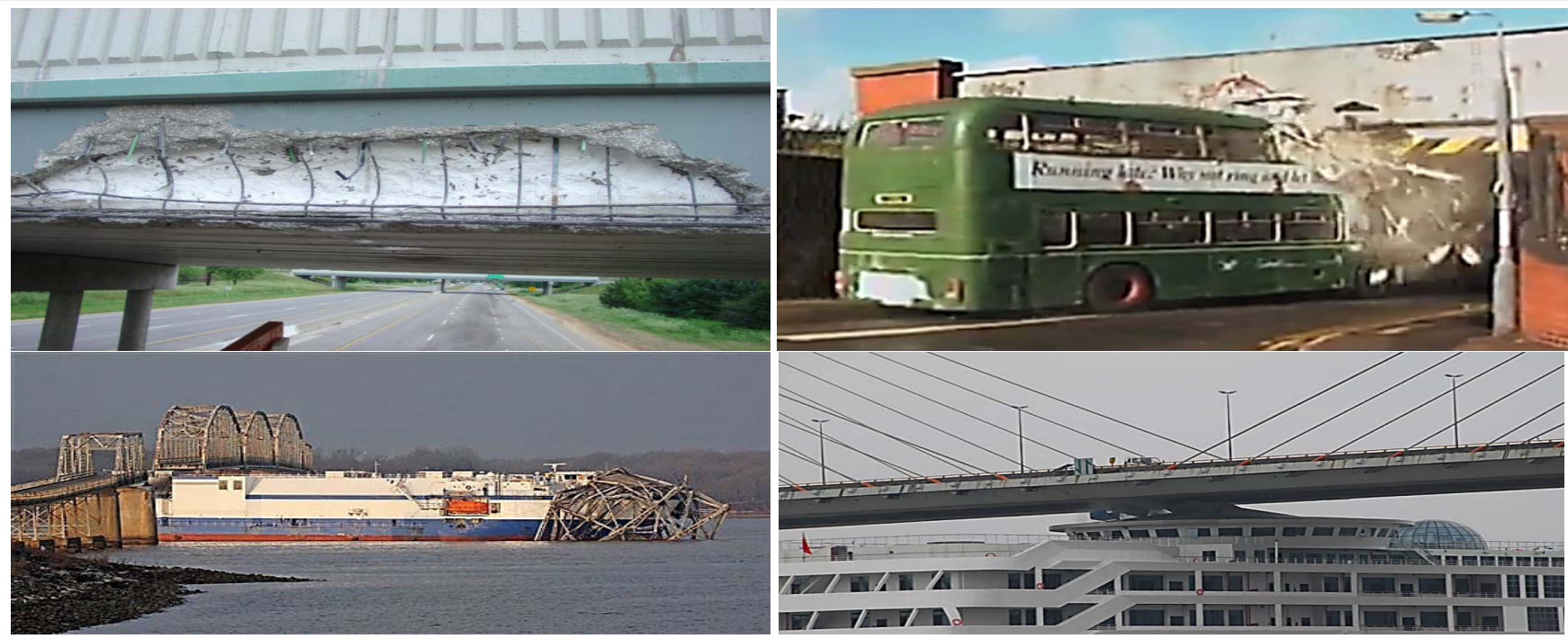

Figure 13: Impact damages in the concrete bridge girders by over-height trucks and buses.

a. Collision damages of highway bridges by buses and trucks

b. Collision damages of highway bridges by ships 
system $\left(\mathrm{I}-\mathrm{Lam}^{1 *}\right)$ to act as a scarifying impact system for reinforced concrete members. The system was presented to the Federal Highway Administration through Ohio Department of Transportation as part of the IBRC-T21 program. The four major objectives of this pilot research are: (i) to develop general design for the functionally-degraded collision protection system based on the specified site conditions and construction requirements, (ii) to conduct numerical simulation, optimal design, and quality control tests of the collision protection system [21] (iii) to implement the developed collision protection system in identified damaged bridges or new constructed bridges, and to re-deploy the system if damage occurs, and (iv) to monitor the short- and long-term performance of the collision protection system using smart sensors and actuators and remote sensing technology.

In the full-scale impact evaluation phase, the concrete beam was instrumented with two (2) load cells to measure longitudinal force. The sled was instrumented with two (2) longitudinal accelerometers, which were pre-filtered with an analog filter to $200 \mathrm{~Hz}$ as an integral part of the sled firing circuit, and two (2) additional accelerometers: the primary accelerometer for pulse and integrated velocity determination and a backup accelerometer. In addition, the sled was instrumented with one (1) light trap to measure velocity. The tests were filmed by two (2) high-speed digital cameras set to view the test article, and operating at 1,000 frames per second. The four-test series was conducted at the Transportation Research Center (TRC) facility in Ohio using a custom designed test fixture shown in Figure 14. The fixture included a mounted concrete beam, I-Lam interface specimen, and a wooden impactor. Each test was designed to produce an impact speed of $20.0 \mathrm{~m} / \mathrm{s}$ ( $\sim 45 \mathrm{mile} /$ hour $)$ between

$1^{*}$ US Patent Pending the wooden impactor and the I-LAM interface sample. A single test was performed under the same conditions with the wooden impactor striking the concrete beam.

Results of the full-scale tests confirmed the success of the I-Lam system in protecting the RC beam from both localized and global damages. The as-built unprotected beam experienced severe damages with major concrete spalling and distortion of the steel reinforcement. As shown in Figure 15, minimum damage occurred to all I-Lam protected beams specimens. Only surface evenly distributed flexural hair cracks were observed, especially at the back side of the beam (tension side).

Based on the success of the I-Lam system, Ohio Department of Transportation (ODOT) has approved the installation of the system on one of problematic bridges in Ohio. Figure 16 shows the installation procedures for the I-Lam system.

Hybrid LDPE/FRP collision protection system for bridge RC piers: Several marine applications using recycled hybrid systems were constructed as demonstration projects by the US Army Corps, US. Navy, port authorities in USA (e.g. Port Wanimaie, Delaware Port Authority, etc.) and recently, California Department of Transportation (Caltrans). Caltrans introduced a new structural application for highway bridges where recycled LDPE/FRP hybrid beams (or camels) are used as a protection system for highway bridge abutments from potential impact by ships and barges. A pilot study aimed at evaluating both the service and the ultimate behavior of recycled Low-density Polyurethane (LDPE) beams reinforced with glass fiber reinforced polymer (GFRP) composites rebars [10]. The objective of this study was to conduct pre-qualification full-scale tests for this hybrid system forship collision protection system for Oakland Bridge and other
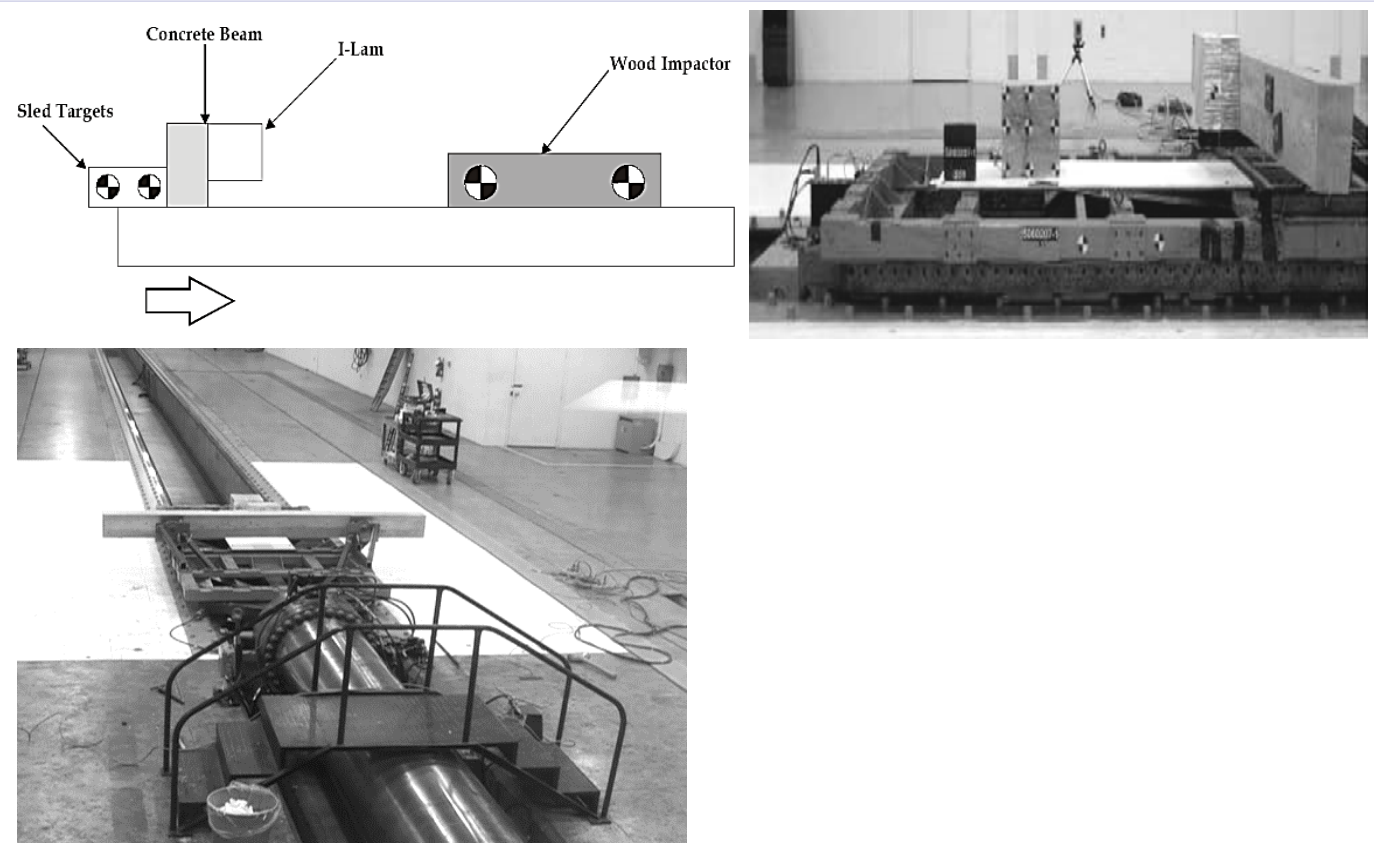

Figure 14: Typical test setup for full-scale impact tests. 


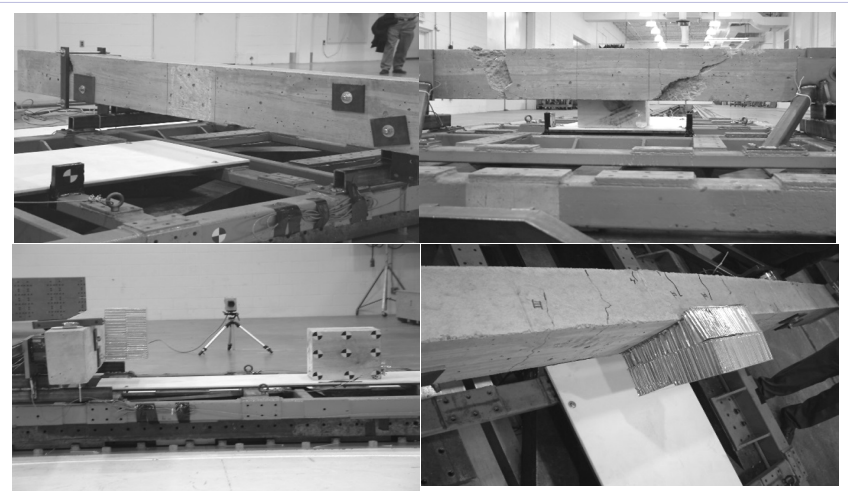

Figure 15: Comparisons of unprotected and I-Lam protected reinforced concrete beams before and after impact.

a. As-built unprotected beam before impact

b. As-built unprotected beam after impact (severe damage is observed)

c. I-Lam protected beam before impact

d. I-Lam protected beam after impact (only minor cracks are observed)
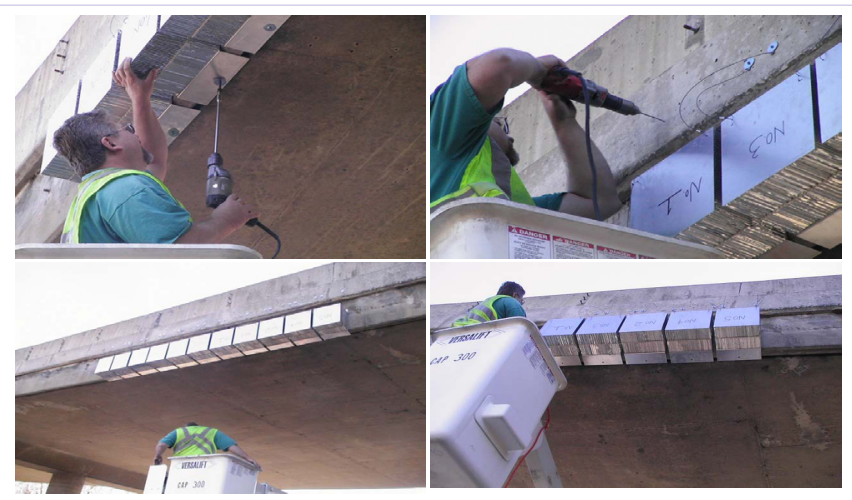

Figure 16: First field application of the I-Lam over height collision protection System in Ohio, USA.

California bridge piers (Figure 17). The study comprised of largescale experimental evaluation as well as the development of a simple closed-form analytical model capable of predicting the flexural behavior of the hybrid beam. In the experimental program, two different composite reinforcement details were evaluated and full-scale specimens were subjected to four-point quasistatic loading/unloading and loading-to- failure protocols (Table 1). In addition, axial tensile and compression coupon tests were conducted to characterize the short-term mechanical properties of LDPE matrix. All large-scale specimens were inspected for any manufacturing defects and voids prior to testing, and measurements of each specimen were recorded. Displacement, strains and loads were continuously monitored and collected during all tests using a computerized data acquisition system. In all full-scale tests, the behavior of the hybrid beams was linear up to about $80 \%$ of the ultimate load, after which the behavior became nonlinear up to ultimate load. No failure or cracks were observed in the LDPE plastic matrix, and the governing mode of local damage was in the form of relative slippage of the FRP rebars at the ends, especially the top compressive reinforcements which, accordingly, resulted in appreciable stiffness loss (Figure 18). Due to the very large deformation of the hybrid beams, the maximum applied load for the tests was limited by the actuator stroke capacity. An analytical model was developed to predict the flexural behavior of the hybrid system. The analytical model is based on deformation compatibility and force equilibrium using section analysis procedure.

\section{Structural upgrade of steel members using FRP composites}

\section{General}

Despite its great potential, limited information is available on bonded fiber-reinforced-polymer composite to steel. A pilot project aims at investigating the feasibility of using a combination of polymer composites, high-strength adhesives as strengthening system for upgrading the structural performance of bridge steel members has been conducted. In addition to the benefit of upgrading the structural capacity of steel members, results of a prior Federal Highway Administration (FHWA) sponsored research study indicated that attaching a cover plate to the tension flange of a steel girder with longitudinal welds along the central region, and with friction-type high-strength bolted connections at the non-welded ends, could increase the fatigue life by a factor of 21 over that of conventionally end-welded cover plate. Accordingly, end-bolted cover plates have Category B fatigue strength, whereas end-welded cover plates have Category E strength.

The use of adhesives provides attractive features for strengthening existing under-rated bridge steel members. This includes the ease of applications, minimizing heavy equipment, minimizing or eliminating the need for making holes or using bolts. As a result, this approach can provide the structural engineers with quick and low cost fix for different members such as bridge steel girders and columns. The motivation of this research study was initiated by the urgent need to increase the static flexural capacity of the steel girders of the Sauvie Island Bridge.

A pioneering research project on the use of composites and high-strength adhesives in seismic repair and rehabilitation of

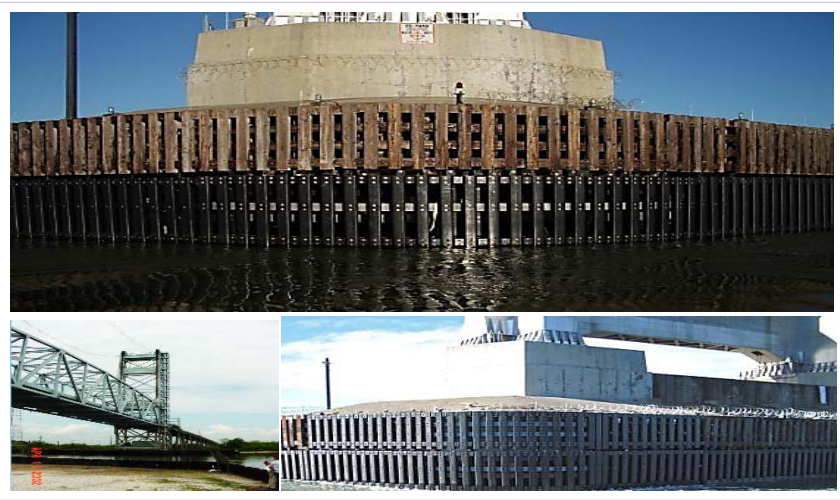

Figure 17: Examples of field application of LDPE-GFRP for bridge collision protection. 


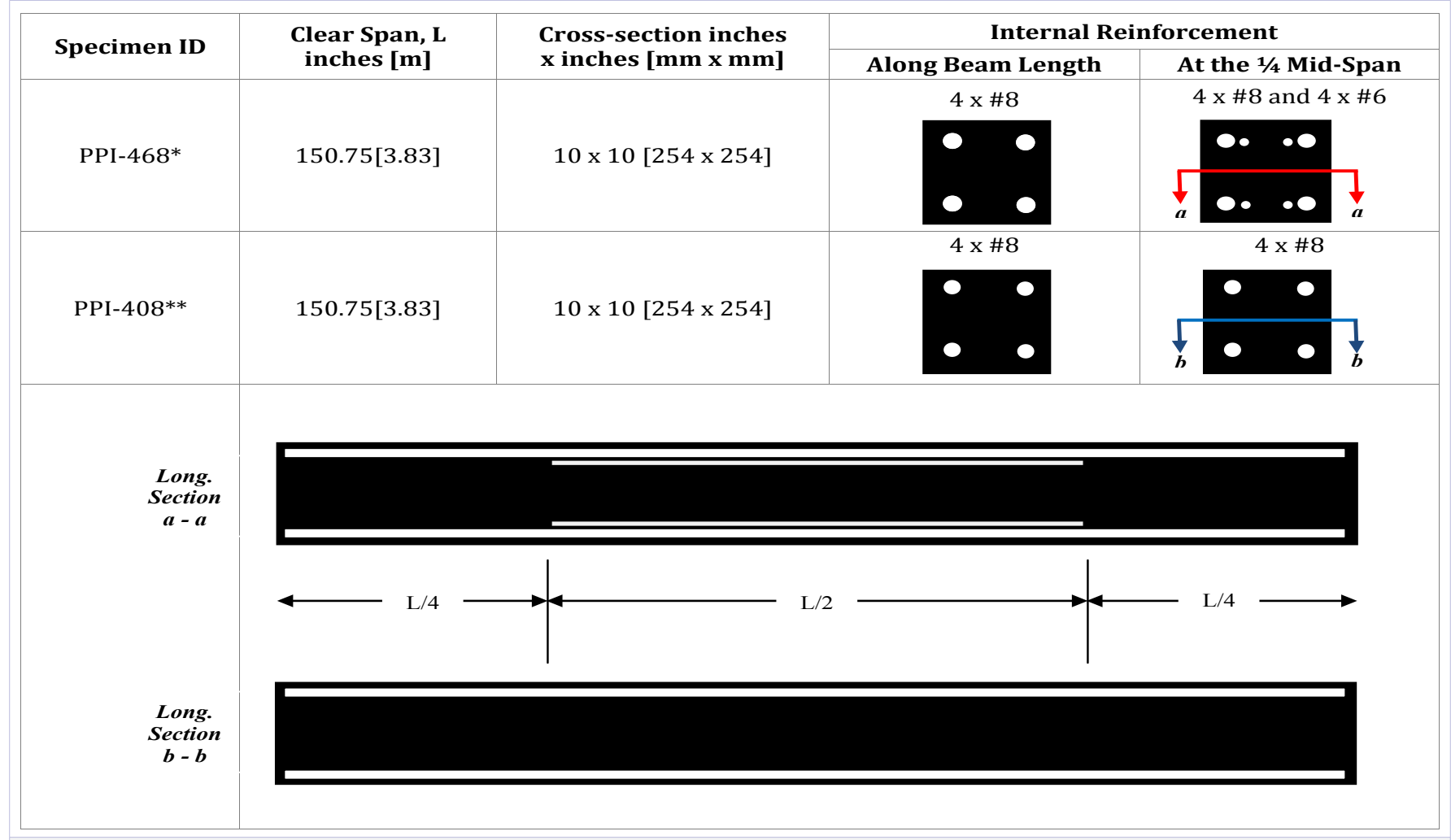

Table 1: LDPE/FRP hybrid beams test matrix. ${ }^{*}$ Cover $=1 "$ [25.4 mm], **Cover $=3 / 4 "$ [19 mm]
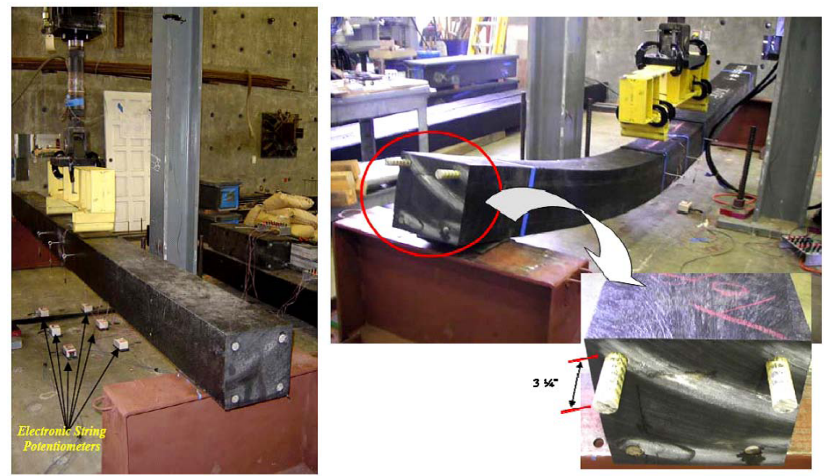

Figure 18: Typical LDPE/GFRP beams test setup and failure mode.

welded steel moment frame connections was initiated by the author [22,23]. Full-scale test results indicated that the used of bonded carbon/epoxy stiffeners resulted in an increase of more than $25 \%$ of the undamaged welded steel connection strength. In addition, the ductility of the repaired connections was enhanced with a plastic rotation capacity of more than 0.025 rad., which was required by Federal Emergency Management Agency (FEMA). One of the first investigations on the use of carbon/epoxy strips in strengthened steel girders was reported by Sen R \& Liby L [24]. A case study on the use of composites in upgrading the structural capacity of steel girders was reported by Garden HN \& Shahidi EG [25]. In this case study, the steel girders were heavily corroded and were repaired, after cleaning and geometrical restoration, by composites that were applied using a vacuum bagging method. Whether this repair was appropriate given the advanced corrosion stage of the repaired, is still questionable.

Tavakkolizadeh AM \& Saadatmanesh H [26] presented the results of a study on repairing steel girders using precured carbon/ epoxy strips. In this study, a total of three large-scale composite (steel/concrete) girders were repaired using different composite strengthening ratios with different degrees of simulated damages were evaluated. A similar study was conducted by Photiou N [27] on artificially degraded steel box beams using prepreg carbon/ glass U-shaped laminates. Test results showed a significant increase in the strength and stiffness of the repaired beams. The use of high-modulus carbon/epoxy laminates for strengthening steel members and towers was studied by Schnerch D, et al. [28] \& Peiris NA [29]. Zhao XL \& Zhang L [30] presented a state-of-theart review on FRP strengthened steel structures. It was concluded that further research is needed specifically on understanding the bond-slip relationship; the stability of CFRP strengthened steel members, and fatigue crack propagation modeling.

\section{The H-Lam System ${ }^{2 *}$}

The innovative sandwich system was developed by the author specifically for steel strengthening applications. The reinforcing honeycomb polymer composite panels consist of high strength composite facing sheets bonded to a lightweight high density/high strength core material. The H-Lam panels were

2 *US Patent Pending \# 60-146,830 
designed such that they are both thermally and mechanically balanced. The face sheets of the composite sandwich panels are comprised of $0^{\circ} / 90^{\circ}$ carbon/epoxy laminates with E-glass/ epoxy thin laminates at the interface with the steel girder and the aluminum honeycomb core. The reason for using $90^{\circ}$ cross laminates is for stability of the unidirectional laminates during both the fabrication and during service.

The H-Lam system used in this application has an E-glass/ epoxy cover layers to protect the carbon-based composite panel from galvanic corrosion (the galvanic corrosion occurs upon direct contact of the carbon/epoxy to steel in the presence of moisture, which in this application is unavoidable). In addition, the H-Lam panels have an E-glass peel-ply (Figure 19) to protect the pretreated face sheet to be bonded to the steel bottom girder. This functions of the added peel-plies are: i) to ensure a high quality shop surface preparation of the composite face, ii) to protect the composite panels from damages and surface contamination while handling and shipping and iii) to minimize the field surface treatment.

Unlike the general-purpose epoxy used for the off-the-shelf CFRP (Carbon/epoxy Fiber Reinforced Polymer) composite strips system, which was originally developed for concrete and masonry, the H-Lam adhesive system was engineered specifically for steel strengthening application. In addition, the H-Lam system offers the choice of using either bond-only or bond/bolted joint between the composites and the steel member. However, in this application, the bond-only system was used to avoid any alteration to the existing steel girders.

In designing the adhesive system, several criteria were considered including: i) the surface preparation and treatment requirements (ease of field application), ii) viscosity (workability), iii) temperature variation, and long-term durability requirements including wet environment, iv) toughness and strain compatibility with steel and composites, v) fatigue resistance and vi) strength and stiffness requirements. Instead of the general-purpose epoxy adhesives used for bonding the CFRP strips, a methacrylate adhesive system was designed and used for bonding the H-Lam panels.

The cyclic results indicated the stability of the bond line of the H-Lam strengthened beam at both zero and maximum shear stresses locations, while the CFRP strips may have shown instability, at end locations where shear stresses are maximum. The results of the ultimate tests indicated that the use of the composite system increases the flexural capacity of the control beams. The net strength gain for specimens strengthened with the H-Lam system was almost double of the strength of the beam strengthened with the CFRP strips (27.5\% vs. $15.4 \%$ as compared to the ultimate capacity of the control steel beam). Although, test results indicated that the $\mathrm{H}$-Lam strengthened beam system resulted in an increase in toughness up to $45 \%$ as compared to the control specimen while the CFRP strips strengthened had $42 \%$ lower toughness as compared to the control specimen (Figure 20). No laminate or bondline failure occurred under both cyclic and quasi-static ultimate loadings and the failure was in the form of local buckling of the top flange as shown in Figure 21.

\section{Flexural upgrade of sauvie island bridge steel girders using H-Lam technology, Portland, Oregon, USA}

Based on the successful verification tests results, the H-Lam system was approved by the Bridge Department for actual bridge installation. The field application was performed on selected

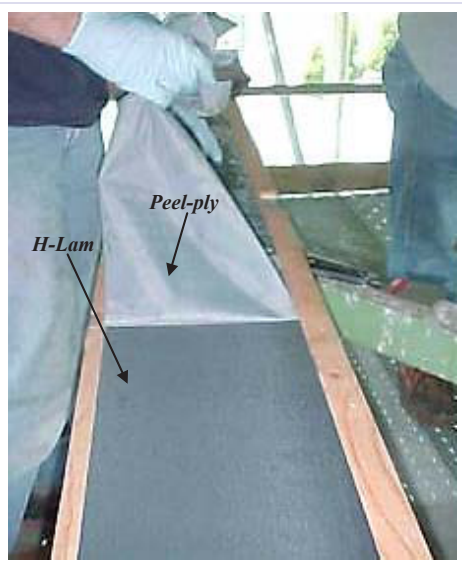

Figure 19: The H-Lam peel-ply.

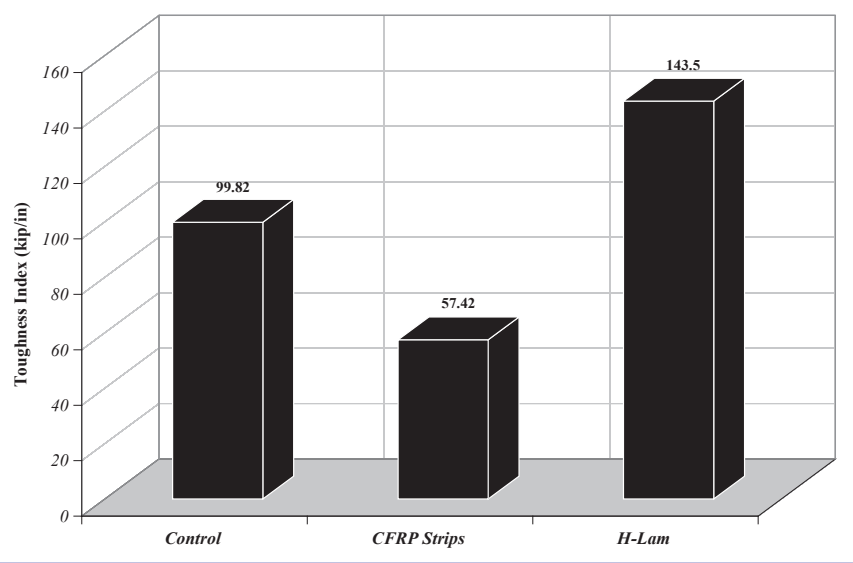

Figure 20: Toughness comparison between the three half-scale specimens.

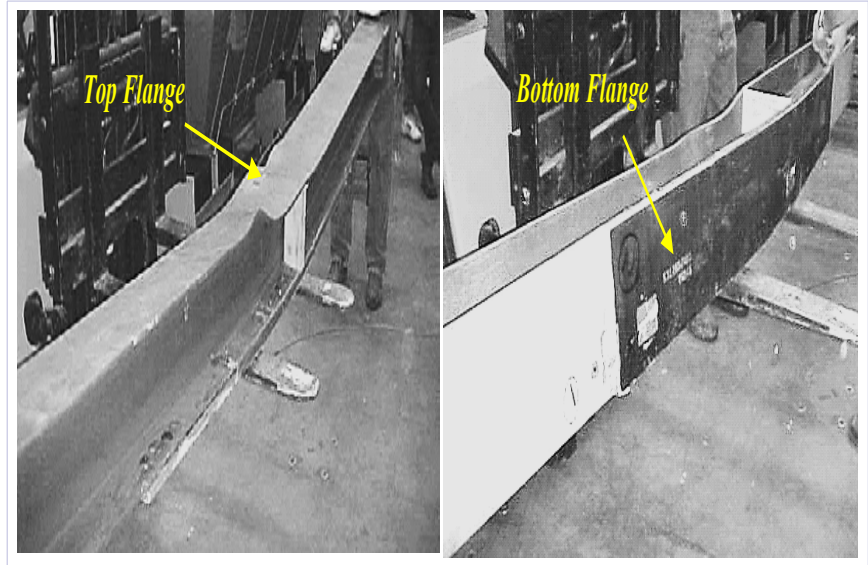

Figure 21: Ultimate failure of the h-lam strengthened beam specimen. 
steel girders of a selected span of the Sauvie Island Bridge (Figure 22). All composite panels, adhesives and tools were transported to the site at the same day of application. The field application took place on a Sunday to ensure minimum traffic interruption. In addition, a traffic restriction (from 12 p.m. to 9 p.m.) for all vehicles over 10 tons was posted on the bridge two weeks prior to the construction date. Temporary clamping steel/plywood fixtures were used for applying pressure to the composite panels during curing and were removed after one day of application. The application was completed in 5 hours and the panels were instrumented with strain gages in different locations for the third ongoing health-monitoring phase. In addition to strain monitoring, several composite samples were adhered to steel using the same types of adhesives that were subjected to the same field environment. Frequent pull-off tests are being performed to monitor the long-term bondline strength at different environmental exposures. Detailed information on this project is reported by Mosallam AS [31].

\section{Repair \& rehabilitation of wood members using FRP composites}

As compared to other structural applications of polymeric composites, limited information is available on structural behavior of wood members strengthened with polymer composites. One of the first applications was initiated in mid-1990, where E-glass/ epoxy laminates were used to restore damaged wooden utility poles and this application was further studied by Polyzois D \& Kell JA [32]. Similar application of strengthening wood piles with composites was also investigated by Lopez-Anido R, et al [33]. One of the pilot applications for developing a hybrid gluedlaminated wood by introducing thin laminates of E-glass/epoxy composites between the wood layers was introduced by Tingley D [34]. During the past two decades or so, several papers were published discussing critical issues related to this application. For example, Gilfillan JR, et al. [35] studied the structural behavior of several Irish-grown Sitka timber beams strengthened with both composites and steel. These beams were evaluated under both short- and long-term mechanical loading. Experimental results indicated that an appreciable strength gain was been achieved for beams strengthened with FRP composites. Triantafillou TC [36] studied the application of unidirectional and cross-ply FRP composites in enhancing the shear strength of glulam wood members. The experimental program included a total of twentyone small-scale beam specimens that were subjected to 4-point loading regime. A simple analytical procedure was proposed and results were compared with experimental values.

A new generation of advanced composites for structural upgrade of wood members was developed by Mosallam AS (2013) similar to the H-Lam system discussed earlier for strengthening steel members. However, the fiber architecture of face sheets and core material type was different for wood applications. This repair system utilizes the concept of thin sandwich panels that is bonded and also screwed to the wood member (Figure 22). The advantages of using sandwich panels in this application includes: (i) ease of application, (ii) increase in quality control of the prefabricated materials and shop pretreated surfaces, (iii) light-weight features, (iv) the presence of stiffened holes allows for drilling metal screws or nails that will act as both shear connectors and prior to adhesive curing as a temporary clamps, (v) superior fire properties due to higher glass-transitiontemperature $\left(T_{g}\right)$ and the use of phenolic matrix, and (vi) overall all economic advantages. The face sheets of the sandwich panels are fabricated from a low-smoke carbon/phenolic laminates bonded to an aramid honeycomb core using high-temperature, high-press manufacturing process. The fiber architecture of the two face sheets were in the form of cross-ply $\left[0^{\circ} / 90^{\circ} / \mathrm{c}\right]_{\mathrm{s}}$ (c=half of the core thickness) thin laminates with a unit thickness of 0.75 $\mathrm{mm}(0.03$ "). Equal fiber volume fractions for both longitudinal and transversal directions was used, with an overall fiber volume fraction for both directions equal to $70 \%$ for face sheet laminates, assuming a zero void ratio.

In developing this Honeycomb Laminated system (referred to as H-Lam hereafter), several design parameters were considered including: (i) resin compatibility with wood, (ii) pre-treatment of the composite surface to be bonded to wood, (iii) providing selfclamping mechanisms to hold the H-Lam in place during the antigravity application at the site, (iv) fire resistance, (v) economic considerations and (vi) strength and stiffness requirements. These design targets were achieved by optimum design of face sheets and core; pretreatment of the face sheets, selection of fire retardant matrix and core materials, introduction of central through-the-thickness stiffeners and holes at equal spacing of $25.4 \mathrm{~mm}(1$ ") along the span of the panel. With this arrangement, the applicator is able to use nails or screws to hold the H-Lam in position after applying the low-viscosity primer and the highviscosity adhesives in addition its partial role as mechanical shear connectors (Figure 23). The width of the H-Lam is $152 \mathrm{~mm}$ (6") and the total thickness of the H-Lam is $10 \mathrm{~mm}(0.4$ ") with an average face laminate thickness of $0.74 \mathrm{~mm}(0.029 ")$.

Two types of composites; wet layup and sandwich panels, and two lamination schedule; unidirectional and bidirectional, and two lamination geometry, U-laminate and flat laminates were evaluated. For "flexure-shear" wood beams repaired and retrofitted with bidirectional, carbon/epoxy U-shaped wet layup

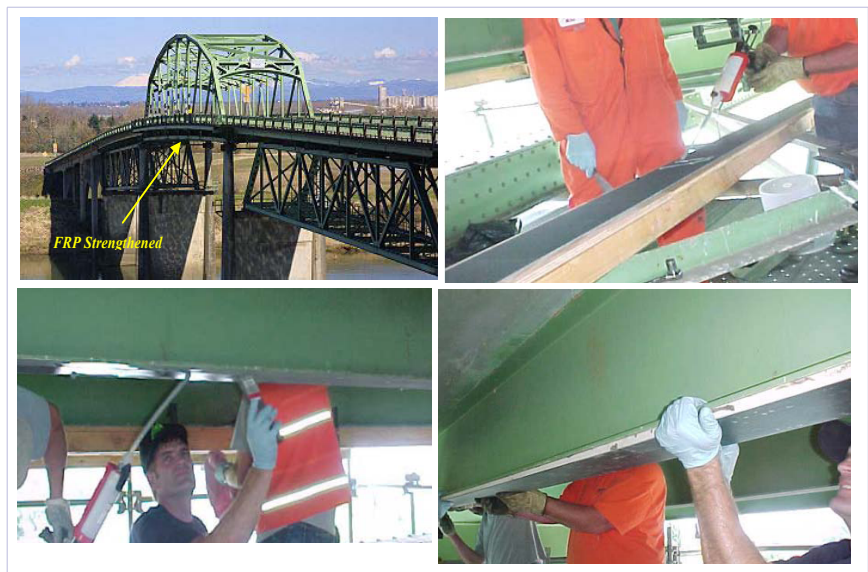

Figure 22: Field application of the h-lam system for the sauvie island bridge, Portland, Oregon, USA. 

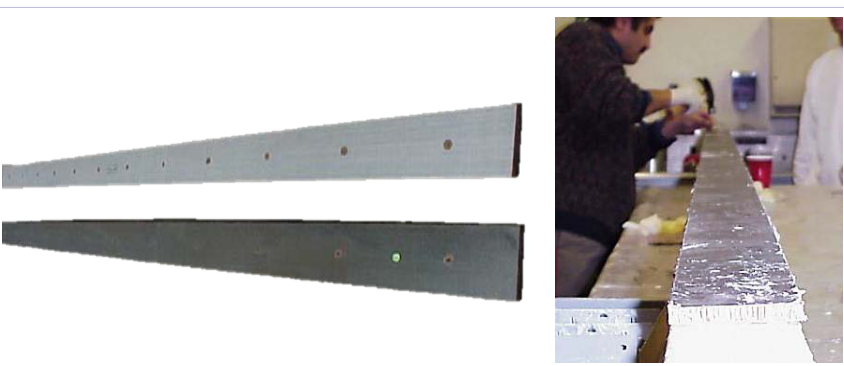

Figure 23: Sandwich composite panels for strengthening wood members.

laminates, a total of eight 203 mm X 203 mm X 3.0 m (8” X 8" $X$ 10') Douglas Fir (Dug Fir) Larch \# 1 wood beams were tested to failure. Experimental results indicated that, in general, the use of composites as external repair and rehabilitation elements resulted in an appreciable increase of both strength and stiffness of the as-built wood beams. For example, test results indicated that an increase, up to $180 \%$ of the strength of pre-damaged beam repaired with carbon/epoxy composites is achieved. In addition, the flexural stiffness of the strengthened beam was upgraded to about $150 \%$ as compared to the pre-damaged beam specimen. Figure 24 presents load-displacement curves as-built wood beam and strengthened beams with flat unidirectional CFRP laminate and H-Lam system. As shown in this figure, the H-Lam strengthening system has superior stiffness, strength and toughness as compared to both the as-built and flat CFRP strengthened wood beams.

\section{Repair \& rehabilitation of masonry walls using FRP composites}

One of the successful applications of FRP is upgrading the seismic performance of unreinforced masonry (URM) walls, which are the primary load carrying components of unreinforced masonry buildings. In old building constructions, these walls were primarily designed to carry gravity loads. Due to the absence of any lateral load carrying component, such constructions are generally fragile during ground excitation resulted from seismic events. In fact, a significant damage of these walls is observed in past due to earthquakes [37]. Hence, seismic retrofitting of these buildings is required in order to upgrade their seismic performance and improve the ductile behavior. Experimental research demonstrated that the external application of FRP composite laminates either on single or on both sides of masonry walls can remarkably enhance their in-plane and out-of-plane shear carrying capacity [38,39]. A comprehensive literature review on this can be found in ACI 440.7R-10 [40]. In conjunction, numerical studies have also been performed by developing finite element models to predict the in-plane behavior of FRP retrofitted masonry walls [41]. It is observed that the degree of enhancement of wall capacity greatly depends on several factors such as the wall aspect ratio, masonry type (brick, stone or concrete), retrofitting scheme, type of FRP material used, and application of later alloads (in-plane or out-of-plane). In addition, the purpose of FRP application either to repair partially damaged walls or to retrofit undamaged walls can make considerable difference in wall shear strength enhancement.
Haroun MA, et al. [42] conducted a comprehensive verification experimental program on cyclic in-plane shear of concrete masonry walls strengthened by FRP laminates. In this study, different types of composites including E-glass and CFRP wet layup laminates as well as pre-cured CFRP strips were evaluated (Figure $25 \&$ Table 2). The reported experimental results demonstrated the effectiveness of different FRP materials and lamination schemes in order to externally repair or retrofit URM walls. A significant gain in in-plane shear capacity is observed when the walls are strengthened with FRP composites on either one or both sides of walls. The key experimental observations are: (i) the application of FRP in order to repair the pre-cracked wall resulted in $20 \%$ gain in the in-plane shear capacity in comparison with the as-built wall; (ii) a maximum increase of $35 \%$ is achieved in the in-plane shear capacity of URM walls when the walls are retrofitted with FRP; (iii) due to retrofitting, the ultimate failure mode changes from diagonal cracking of walls (brittle failure in nature) to compression failure at one of the wall toes (ductile failure in nature); (iv) the yield and ultimate displacements of the retrofitted walls are recorded as considerably higher than the same of the retrofitted wall. Figure 26 presents the load-

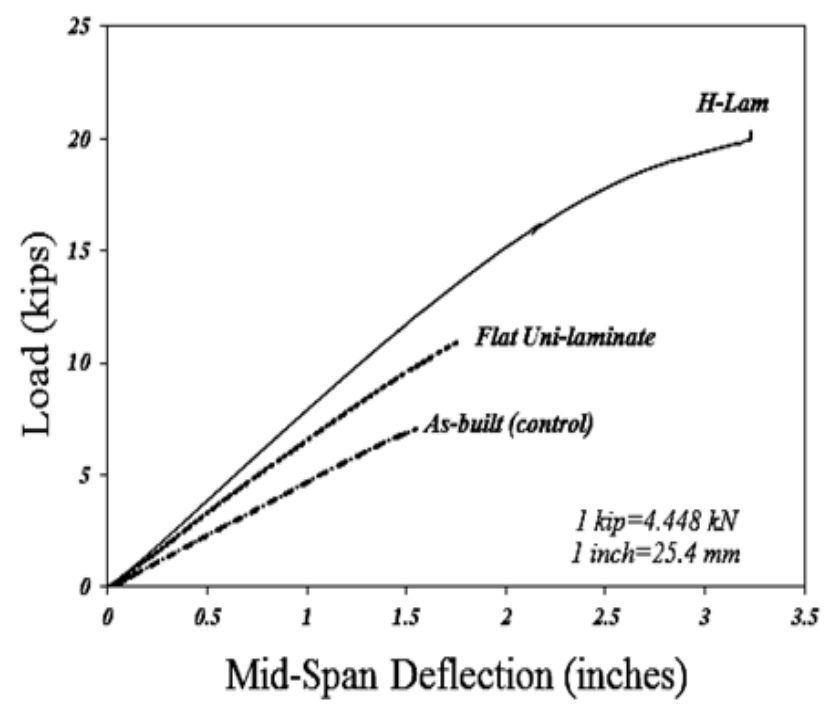

Figure 24: Load-deflection curves for unstrengthened and FRP strengthened wood beams.

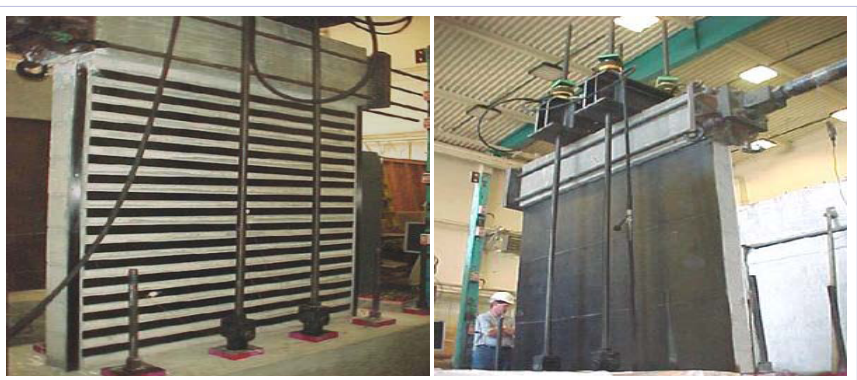

Figure 25: Samples of masonry walls retrofitted with FRP composites: a. Carbon/epoxy procured strips

b. Carbon/epoxy wet layup laminates 
displacement envelops for all wall specimens. Table 1 \& Figure 27 show a summary of the ultimate shear strengths of different masonry walls.

Mosallam AS \& Banerjee S [19] calculated the strength capacities of the walls investigated by Haroun MA et al. [43] using currently available code-based and research-based analytical models. Four analytical models were used according to their applicability for different retrofitting schemes. A comparison of analytical result with experimental observations indicated that analytical models are very case specific and their applications are very restrictive. Thus further studies are needed to develop analytical models that will be generally applicable to a higher population of concrete masonry walls externally retrofitted with different combinations of composite materials and lamination schemes.

Table 2: Summary of ultimate strength values for all masonry wall specimens.

\begin{tabular}{|c|c|c|}
\hline Specimen ID & Specimen Description & $\begin{array}{l}\text { Ultimate } \\
\text { Strength } \\
\text { kips (kN) }\end{array}$ \\
\hline WU1 & Control (Ultimate) & $83(369.18)$ \\
\hline WU2 & Control (Cracked) & $62(275.78)$ \\
\hline WU2-C-R & $\begin{array}{c}\text { Carbon/Epoxy Laminate - Repair (Two } \\
\text { Sides) }\end{array}$ & $100(444.8)$ \\
\hline W3-C-RT & $\begin{array}{c}\text { Carbon/Epoxy Laminate - Retrofit } \\
\text { (Single Side) }\end{array}$ & $95(422.6)$ \\
\hline W4-C-RT & $\begin{array}{c}\text { Carbon/Epoxy Laminate - Retrofit (Two } \\
\text { Sides) }\end{array}$ & $108(480.38)$ \\
\hline W5-E-RT & $\begin{array}{l}\text { E-glass/Epoxy Laminate - Retrofit (Two } \\
\text { Sides) }\end{array}$ & $106(471.49)$ \\
\hline W6-CS-RT & $\begin{array}{c}\text { Carbon/Epoxy Strips- Retrofit (Single } \\
\text { Side) }\end{array}$ & 98 (435.9) \\
\hline
\end{tabular}

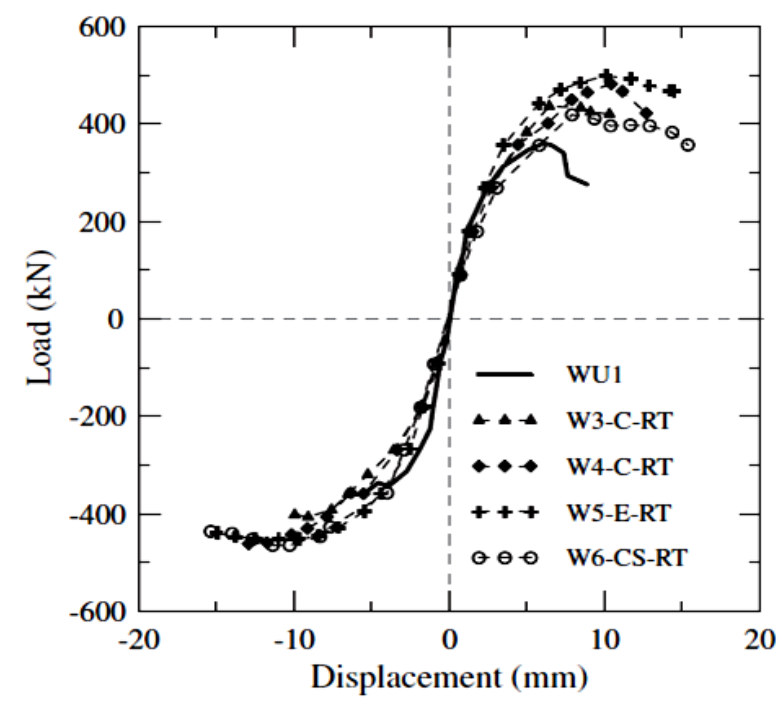

Figure 26: Load-displacement envelopes for as-built and retrofitted specimens.

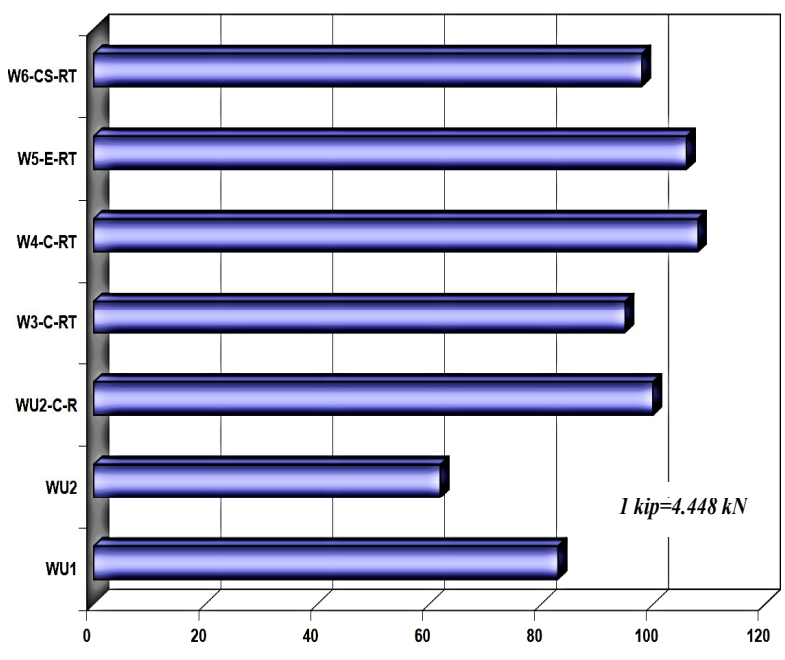

Figure 27: Strength comparison between all masonry wall specimens.

\section{All-composites structural applications}

\section{Background}

In addition to the repair and reinforcement application of composites in construction, composite materials are being used to build the entire structure such as warehouses, buildings, highway and pedestrian bridges and bridge decks as well as other civil engineering structures. One of the popular types of composites in construction applications is pultruded composites. For decades, pultruded fiber reinforced polymeric (PFRP) composites have been used as secondary structural members in several construction applications such as petrochemical plants plate forms, cooling towers structures, and in water and wastewater treatment plants applications. The pultrusion process is a continuous manufacturing process where the saturated fibers are pulled through heated die using continuous pulling equipment. The hardening or gelation of the resin is initiated by the heat from the die producing a cured rigid pultruded profiles that are cut to length by an automated saw. Pultrusion is considered to be the only closed mold process that allow for combining a variety of reinforcement types and hybrid in the same section. Most of the commercially produced PFRP structural shapes are composed of multilayers of surfacing veil or Nexus ${ }^{\mathrm{m}}$, continuous fibers (roving), and continuous strand mat. The typical volume fraction of fibers for "off-the-shelf" sections is in the range of $40 \%$ to $45 \%$. A variety of structural profiles (open and closed-web) are now available similar to steel sections ( H, I, C, L,...). The major reinforcements of these sections are concentrated in the longitudinal direction of the section with minimum reinforcement in the transverse direction. The most common fiber type is the E-glass in the form of rovings and strand mats. However, recently carbon/E-glass composite profiles have been produced in limited bridge applications.

As shown in Figure 28, with few exceptions, the majorities of the off-the-shelf pultruded profiles are similar, in geometry, 
to steel profiles and are commercially available in different sizes and grades. Although the use of unidirectional reinforcement schedule may be satisfactory for lightweight or secondary structural members, it is indeed not sufficient for primary structural carrying members such as bridge decks, girders and columns. Other disadvantages of using thin-walled unidirectional "steel-like" PFRP profiles are the insufficient lateral and buckling resistance of the section. In addition, in the majority of commercially produced unidirectional open-web (e.g. H-profile, Channels, angles, etc.) and closed web (e.g. rectangular and box profiles) there is a lack of fiber continuity between the web(s) and flanges [44-46]. For this reason a premature failure at the web/flange junction is the common mode of failure of such profiles (Figure 29). A comprehensive discussion on this issue is reported by Mosallam AS [47].

\section{Building applications}

Several projects have been constructed entirely using pultruded fiber reinforced polymer (PFRP) composite sections as the main structural elements. One of the early applications is the construction of four PFRP turret towers on top of the Sun Bank Building, Orlando, Florida. Figure 30 shows one of the three-story high towers framing, which was built entirely from pultruded fiber reinforced plastics (PFRP) shapes (H, angles, threaded rods and nuts). All columns and girders were constructed using openweb H sections, which were connected together using FRP bolts and nuts. The use of PFRP composites was the preferred choice because of the electromagnetic transparency and radio wave reflection properties of composites. Due to the non-magnetic properties of PFRP composites, it is commonly used for facilities with delicate instrumentation.

The first residential/office building with PFRP structural profiles was presented as the Eyecatcher Project at the Swissbau'99 Fair in Basel (Figure 31). After the exhibition, the construction was disassembled and brought to its new location at Münchensteinerstrasse 210, Basel where it now serves as a permanent office building. The Eyecatcher all-composite building is open to the public on agreement. The height of the all-composite 5 -story building is 15 meters (49.21 feet) (with a ground floor area of 10 meters X 12 meters (30.48 feet X 39.37

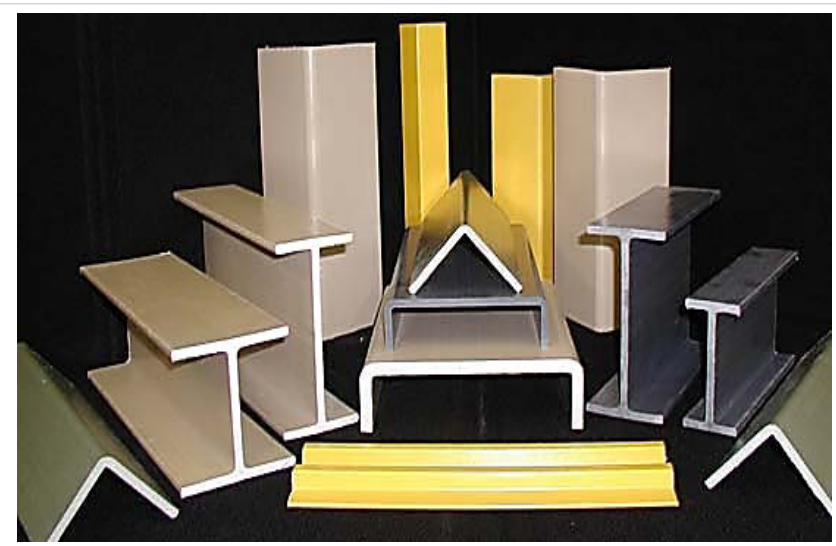

Figure 28: Off-the-shelf pultruded composites.

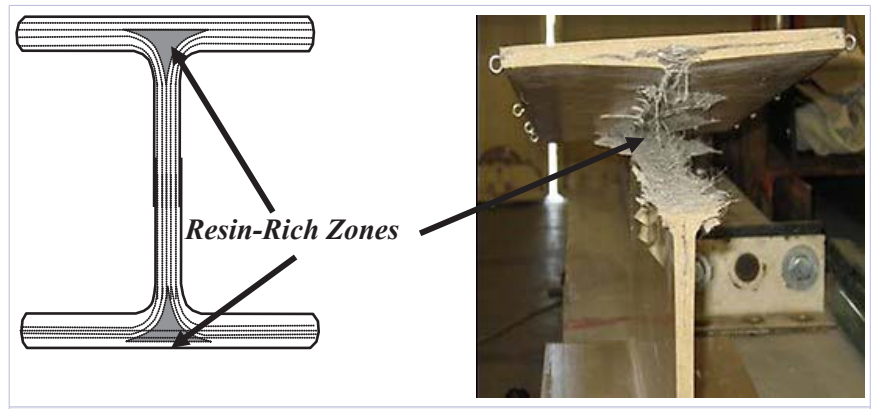

Figure 29: Resin-Rich zones at web/flange junction of unidirectional pultruded profiles.
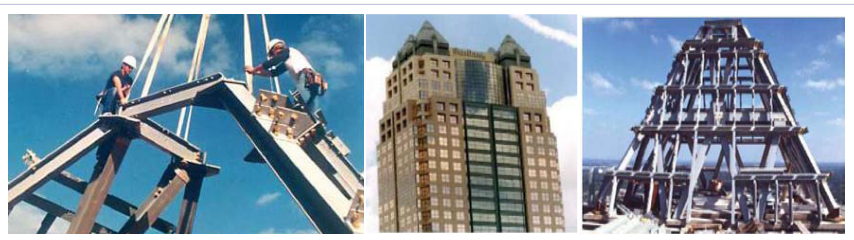

Figure 30: 35' (10.7 m) High x 35' (10.7 m) square base pultruded turrets on top of the sun bank building tower, Orlando, Florida, USA.

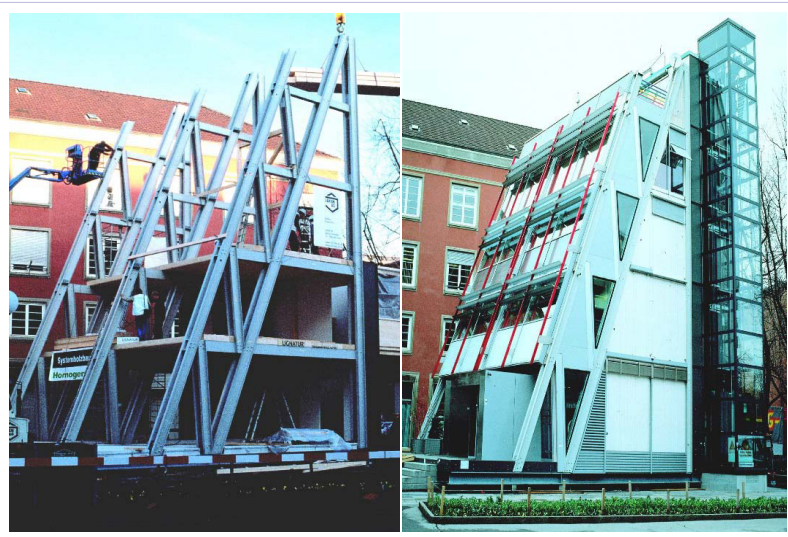

Figure 31: The eye catcher pultruded building during and after construction.

feet). The inclined and vertical columns were fabricated as a build-up section made of one H-profile and two U-profiles. The horizontal frame girders were also built-up sections made of two U-profiles and four flat pultruded plates. In all built-up sections, the pultruded composite profiles were bonded using high strength epoxy and were subsequently bolted together with steel bolts.

\section{Bridge applications}

In the USA, there are over 90,000 weight-restricted bridges U.S. In most cases, there is no enough budget allocated solve the problem by replacing these decks. These bridges are frequently replaced with a modern multi-girder design to restore the route to traffic without weight restrictions. To replace the bridge would have cost $\$ 2.4$ million. In the past few years, FRP composite decks have proven to be an ideal solution of this problem was a cost reduction up to $30 \%$ in additional the tremendous saving in construction time and traffic interruption. In the past two 
decades or so, several US Departments to Transportation (DOT) have utilized composite decks to replace corroded and under rated bridge decks. The US Federal Highway Administration (FHWA) has initiated a major research and development program focusing on innovative technology for extending the service life of US bridges. The program is called Highways for LIFE. A report describing new FRP deck design and application was published in 2013 [48]. Table 3 presents data on some of the different FRP composite decks projects in different states. In the following paragraphs, few examples of utilization of FRP bridge decks are summarized.

The Schuler Heim composite decks, long beach, California, USA: Unlike the majority of previously reported FRP bridge deck applications on the use of composite bridge decks to replace corroded reinforced concrete existing bridge decks [49], the fatigue problem associated with welded steel gratings was the primary motive behind the selection of composites. The lift span of the 55-year old, 1,212-ft (370 m) long four-lane Schuyler Heim steel bridge located in Long Beach, California (Figure 32), have been suffering from localized failure of welded steel gratings due to the high fatigue and impact loads resulting from the heavy truck traffic in and out the Terminal Island of the Long Beach Harbor. It is equipped with a $224-\mathrm{ft}(68.3 \mathrm{~m})$ lightweight opengated steel deck, which lifts to allow ships to pass. The lift has a 5-inch (127-mm) deep deck supported by steel girders spanning the width of the deck every $4 \mathrm{ft}(1.22 \mathrm{~m})$. A dramatic increase in traffic has forced Caltrans to replace the steel deck twice over the last 10 years. The California Department of Transportation (Caltrans), being the leading governmental organization in the U.S. since early 1990's in promoting the use of composite and high performance materials and systems in both seismic repair and bridge applications, decided to take the advantages of the known high fatigue characteristics of polymer composites to establish an effective remedy to this problem. The primary design criteria for Caltrans were limited by weight and profile depth. The weight of the composite deck was limited to $24 \mathrm{lbs} / \mathrm{ft}^{2}(1.15 \mathrm{kPa})$ with a maximum total depth of 5 inches $(127 \mathrm{~mm})$ in order to match the existing grades of the bridge. In addition, Caltrans specified that the new composite deck should be designed to carry 1.25 of the current rated capacity of the welded steel bridge deck (90 kips/400 kN vs. $72 \mathrm{kips} / 320 \mathrm{kN}$ ). According to the American Association of State Highway and Transportation Officials (AASHTO) criterion, the deflection of the new composite deck

Table 3: Samples of FRP composites bridge decks installed in USA.

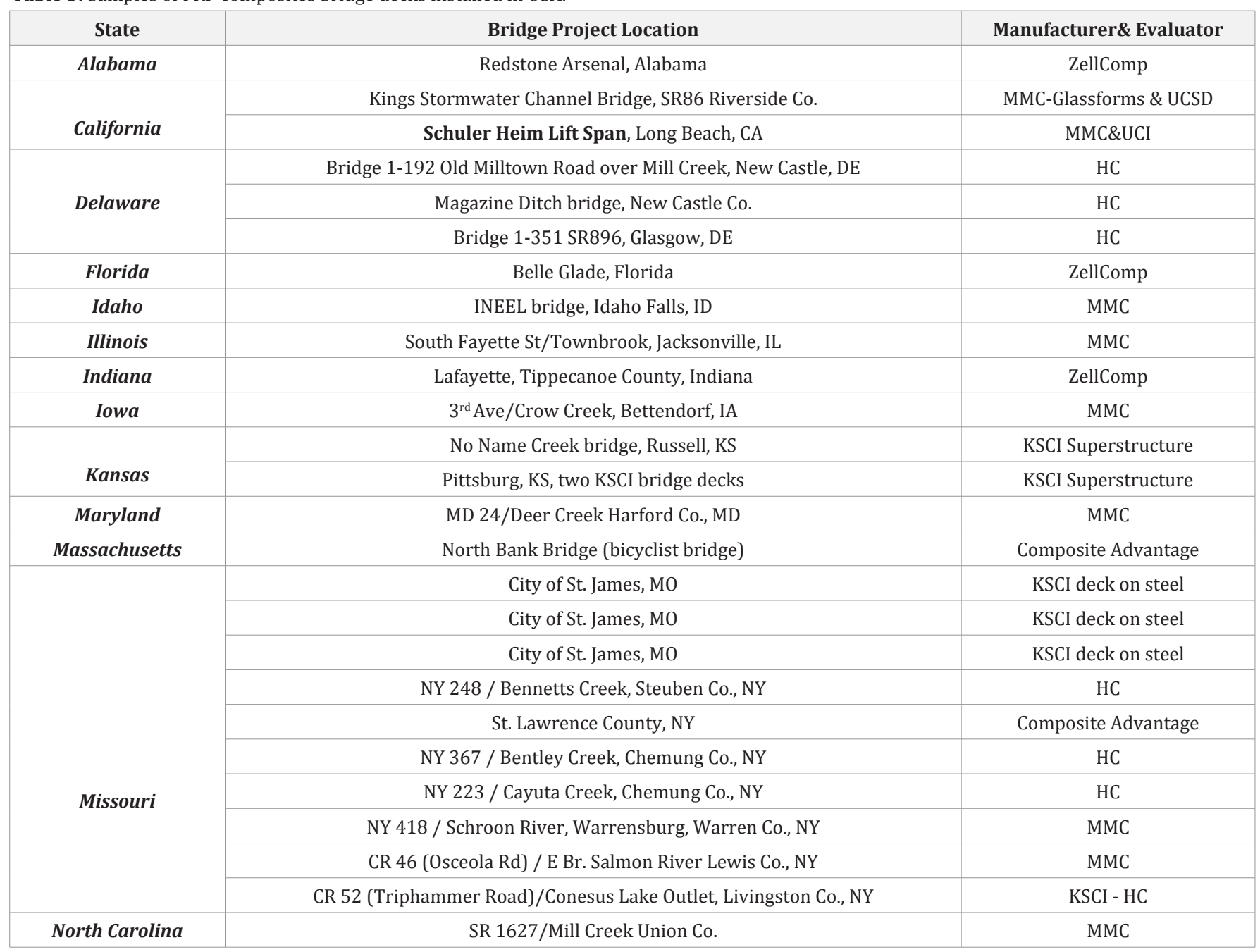




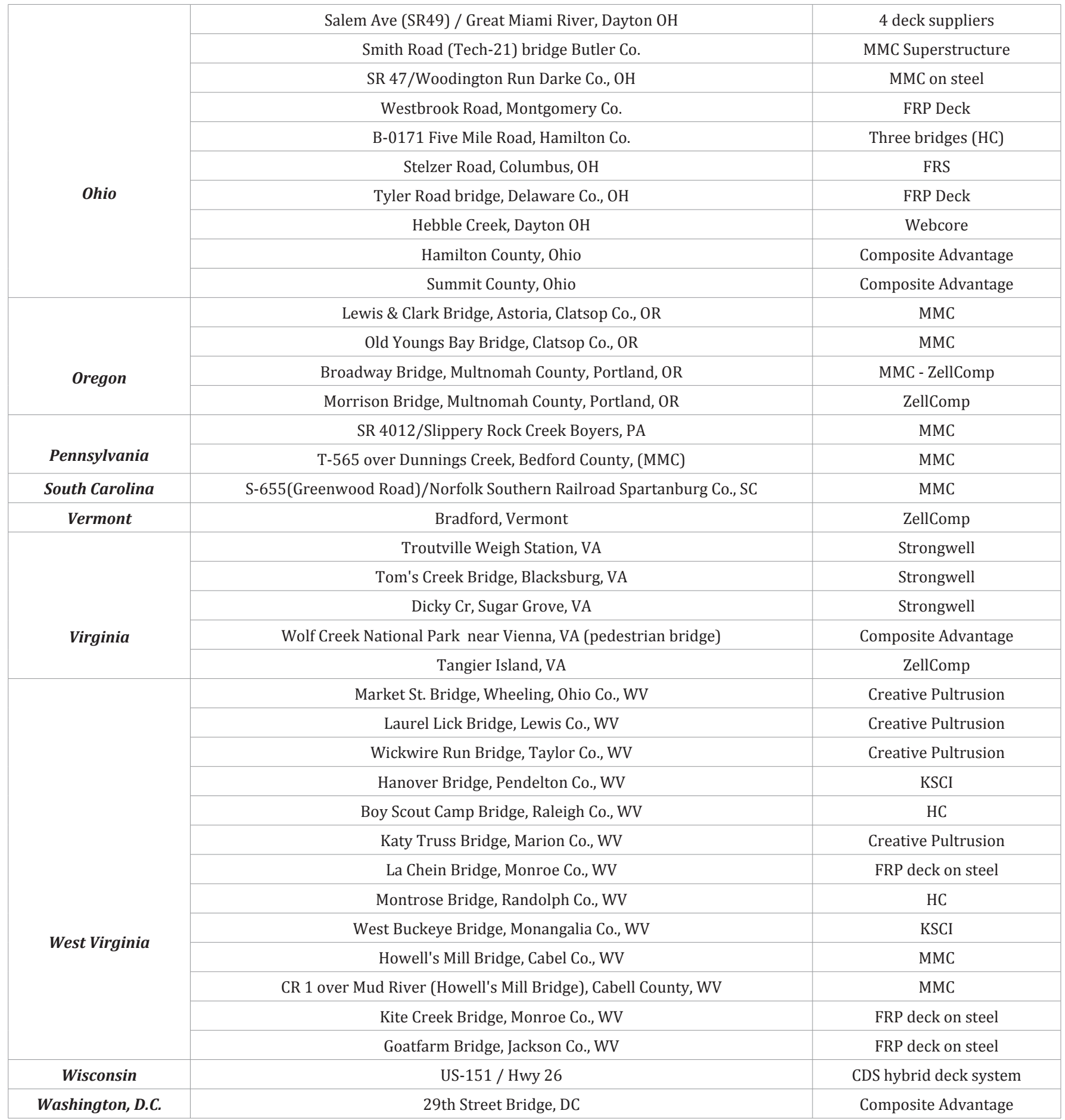

should not exceed its span length divided by 500 (L/500) or in this case $0.096 "$ (2.5 mm) [50].

Full-scale experimental results indicated that the composite bridge deck has exceeded both the predicted design and ultimate capacities. The span-to-deflection ratio at the mid-span was $\mathrm{L} / 738$ based on a span length of 48 " (1.22 m). The average safety factor (SF) of the composite deck prototype was 6 . In all tests, the ultimate failure was initiated either by a punching shear under the loading steel plate, or/and by the delamination of the curved portion of the drop sandwich panel. In modeling the performance of the composite deck, the GENOA progressive failure analysis numerical code was used to perform virtual testing of the composite decks under both quasi-static and fatigue loading conditions. The GENOA progressive failure code succeeded in predicting not only the stresses and strains, but also the major mode of failure observed during the full-scale laboratory tests (Figure 33). The numerical code was also used to design and 
verify the efficiency of emergency repair system for potential damage that may occur during service due to impact loading caused by a drop of a container from a truck. Figure 34 shows the repair simulated model. As shown in Figure 35, the simple proposed repair system was not only successful in restoring the original capacity of the damaged deck, but also exceeded the original capacity by about $25 \%$.

Based on the results of both the experimental and theoretical verification results, the composite deck design were revised and optimized. The final design and specifications documents were prepared and tender documents were issued by Caltrans for qualified contractors. Due to the heavy truck traffic of the Schuyler Heim Bridge, in and out the harbor, it was decided to perform the construction in two consecutive weekends for minimum traffic interruption. Figure 36 presents several photographs that were taken during the construction of composite deck modules. In order to monitor the long-term performance of the composite deck, strain gages were applied to different sections and are currently being monitored.

Chemung county bridge, New York, USA: New York DOT has selected the composite deck solution to replace the old deck of the Chemung County Bridge (Figure 37). This steel truss bridge was originally built in 1940 , with a span length of 140 feet $(42.7$ meters) and a width 24 feet ( 7.32 meters). The average daily traffic on this bridge (AADT) is 3250 with $7 \%$ of this volume is trucks. The engineers in New York DOT Region 6, decided to adopt the FRP composite light weight solution (Figure 38), in addition to repair and painting of steel truss members. After the addition of the FRP bridge deck, the load rating of the bridge raises from the original inventory of HS12 (22 tons) with operating capacity of HS 18 (33 tons) to an inventory of HS 23 (42 tons) with operating capacity of HS 34 (61 tons).

Smith road bridge, Ohio, USA: This was Ohio's first all-

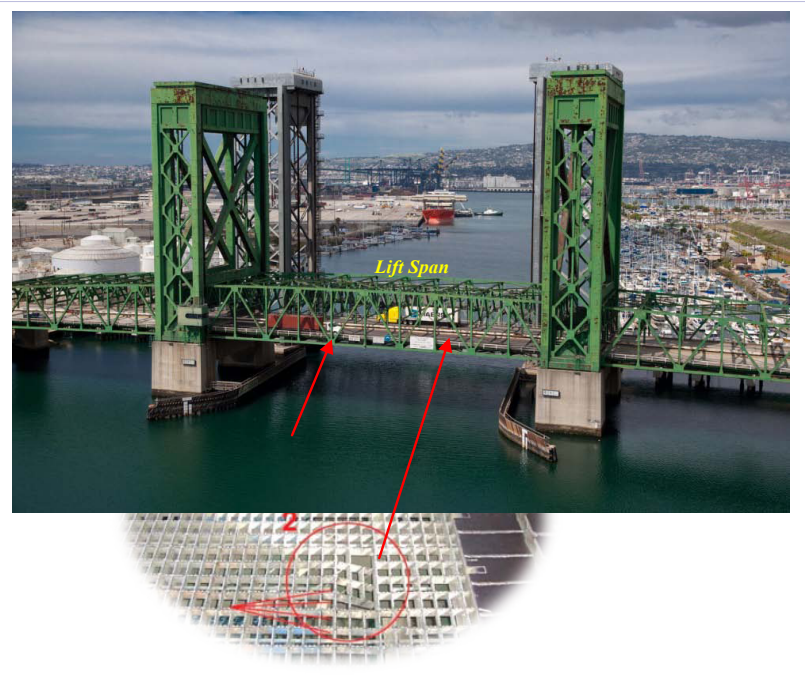

Figure 32: Fatigue damages of the lift-span of the Schuyler Heim highway steel bridge, Long Beach, California, USA.

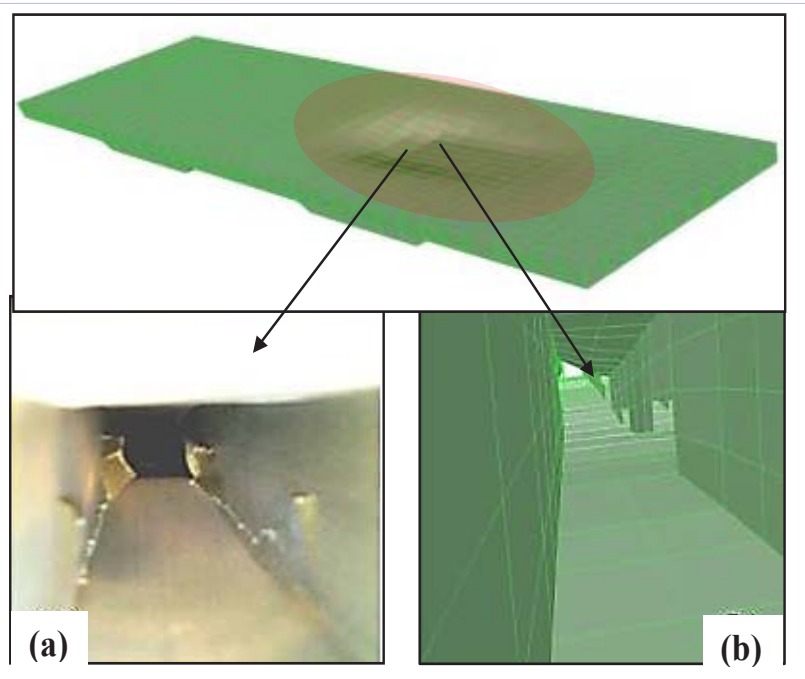

Figure 33: Ultimate failure mode of pultruded sandwich core beams: (a) "Real" Test (b) "Virtual" Test.

composite bridge that was installed in July 8, 1997. Martin Marietta Composites (MMC) designed and manufactured the bridge that was constructed from FRP deck and U-shaped composite beams. This composite bridge has a span of 33 feet (10 meters), a width of 24 feet (7.32 meters), a depth of 2 feet and 9 inches $(84 \mathrm{~cm})$ and weighted less than 22,000 pounds $(9,980 \mathrm{~kg})$. The sandwich composite deck consisted of pultruded composite tubes between two face sheets. The pultruded tubes run parallel with the traffic direction. Three U-shaped composite beams were used to support the sandwich deck (Figure 39). Figure (40) shows the different stages of construction of the bridge.

Fiberline all-composite cable-stayed, Denmark: A similar all-PFRP-composite pedestrian cable-stayed bridge was built by Fiberline Company (Kolding, Denmark) crossing a busy rail line, and was officially opened on 18 June, 1997 (Figure 41). Although, the construction work was restricted to only a few hours during weekend nights due to the busy railway line restricted installation work to only, the bridge was fully installed in only three short nights. The short installation time has illustrated the clear advantages of composites.

Pontresina bridge, Switzerland: In 1997, a 25 meters allcomposite bridge was installed in the mountainous region of Pontresina in Switzerland (Figure 42). The reasons behind the choice of this system is the light weight feature of composite that made it possible to transport the bridge to the mountain area by helicopter and the ease of disassembling during spring season in order to avoid damming and flooding when the melting water carries stone and gravel through the riverbed that used to damage other bridges that were used in the past at that location.

The bridge was transported in two sections, each measuring 12.5 meters ( $41 \mathrm{feet}$ ) one section was glued while the other was bolted. The total weight of the bridge is 3,300 kilograms, with a load carrying capacity of $500 \mathrm{~kg} / \mathrm{m}^{2}$, in addition to a 1-ton snow clearing vehicles allowance. 


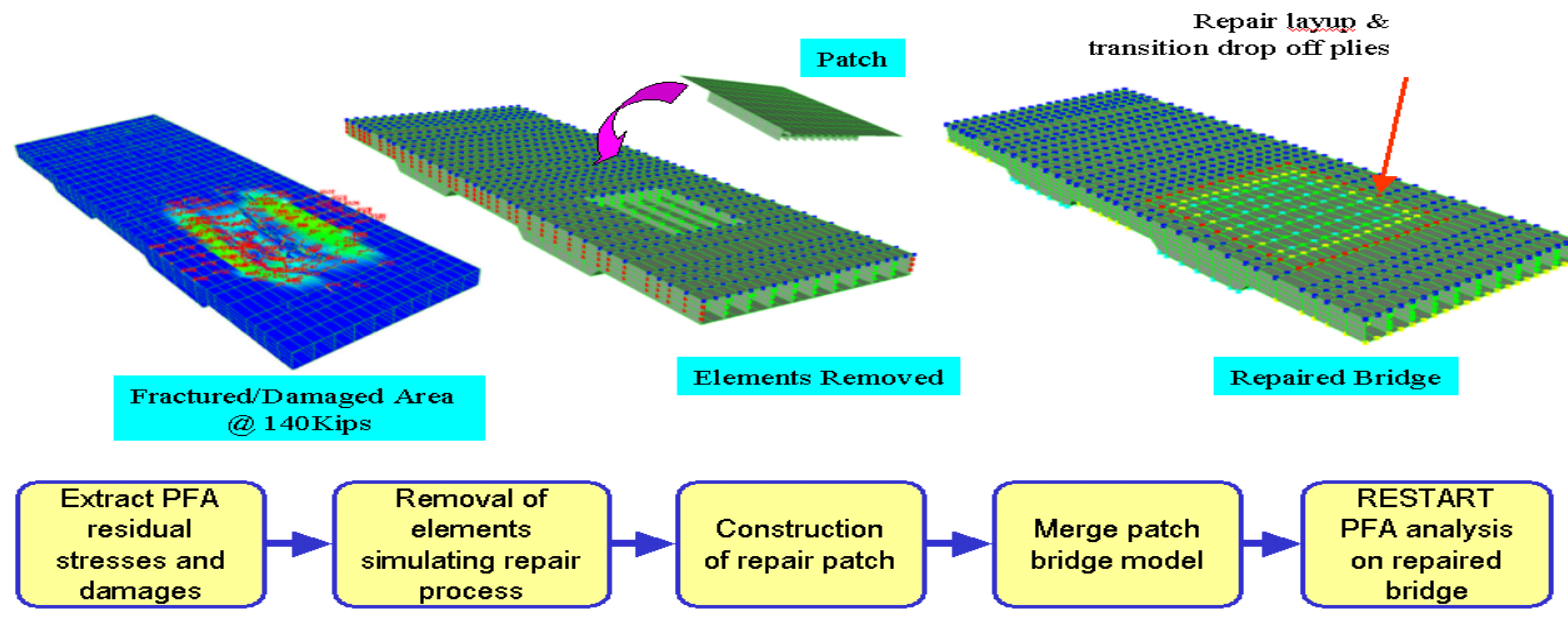

Figure 34: Numerical simulation for developing the emergency repair system for the Schuyler Heim Bridge FRP Deck.

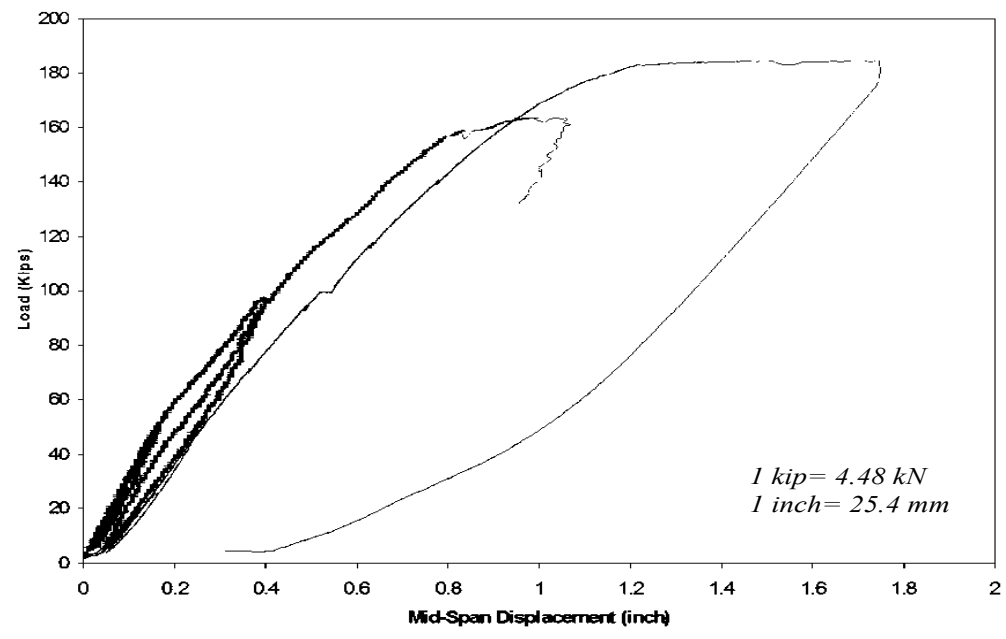

Figure 35: P- $\delta$ Curves for original (undamaged) and repaired FRP deck specimens.

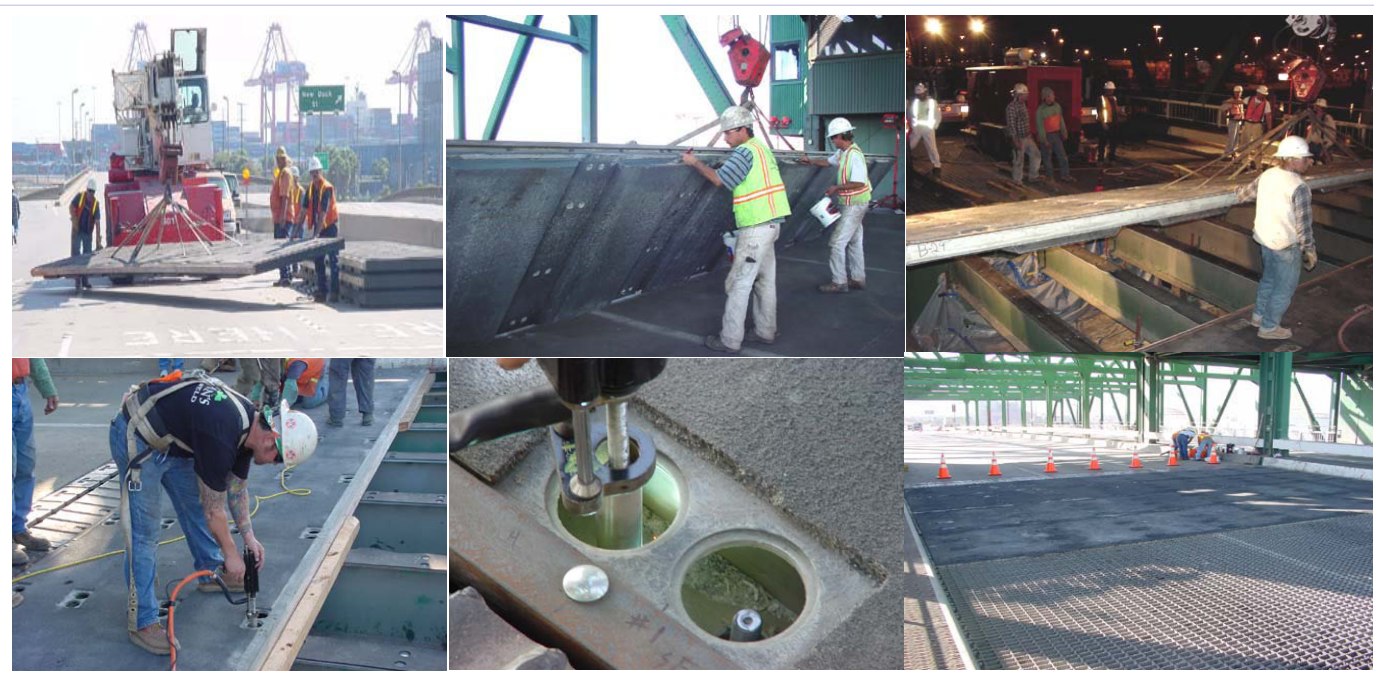

Figure 36: Field installation of the hybrid composite bridge deck at the Schuyler Heim bridge site, Long Beach, California, USA.

Citation: Mosallam AS, Bayraktar A, Elmikawi M, Pul S, Adanur S (2013) Polymer Composites in Construction: An Overview. SOJ Mater Sci Eng 2(1), 25. DOI: http://dx.doi.org/10.15226/sojmse.2014.00107 


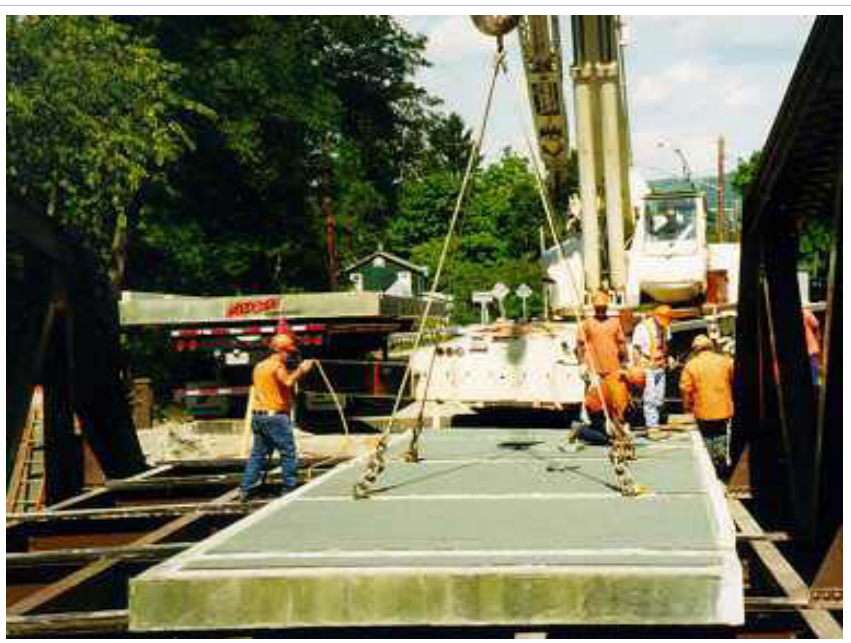

Figure 37: Installation of all-composite bridge deck of NY 367 over Bentley Creek, Chemung County, New York, USA.

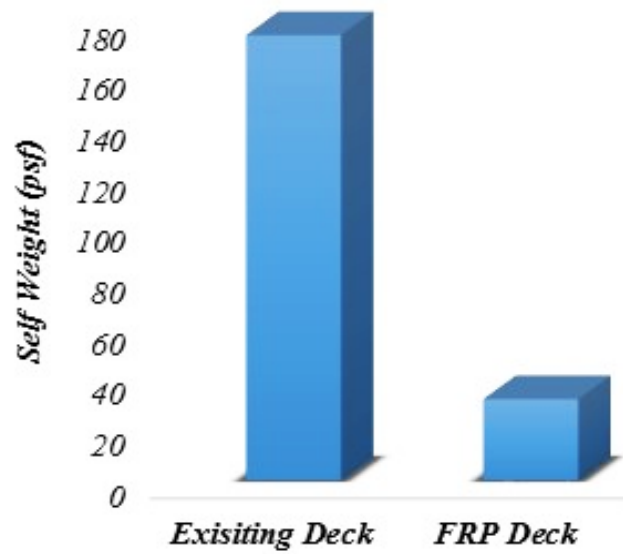

Figure 38: Self-weight comparison between existing and new FRP composite deck of the Bentley creek, New York, USA.

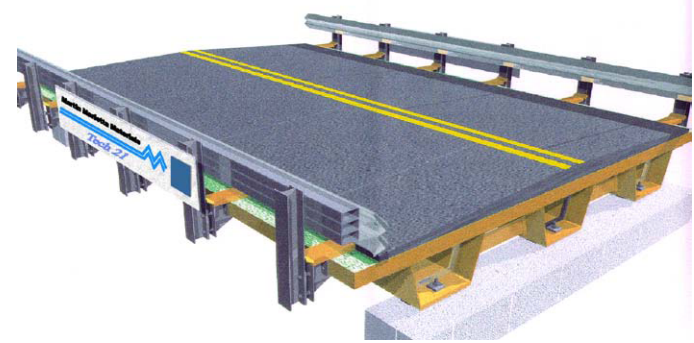

Figure 39: The smith road bridge all-composites bridge, Ohio, USA.

\section{Development of codes, standards and design guides}

In recent years, the construction industry started to realize the potential of using polymer composites in construction applications. Unfortunately, the construction industry and the civil engineers were faced with tremendous amount of difficulties to utilize these materials in the same manner they are used to for the conventional material such as steel, concrete and wood. The major obstacle is the lack of design standards and authoritative codes for the use of these materials in construction applications. Despite the fact that there is a great deal of research and application information available from the aerospace industry for the past four decades or so, still the civil engineers are searching for ways to convince them with the reliability, applicability and the structural efficiency of such materials. For any structural system, design standards are one the essential requirements for professional engineers acceptance. The following paragraph describes the effort of different professional organizations in publishing technical documents in this area.

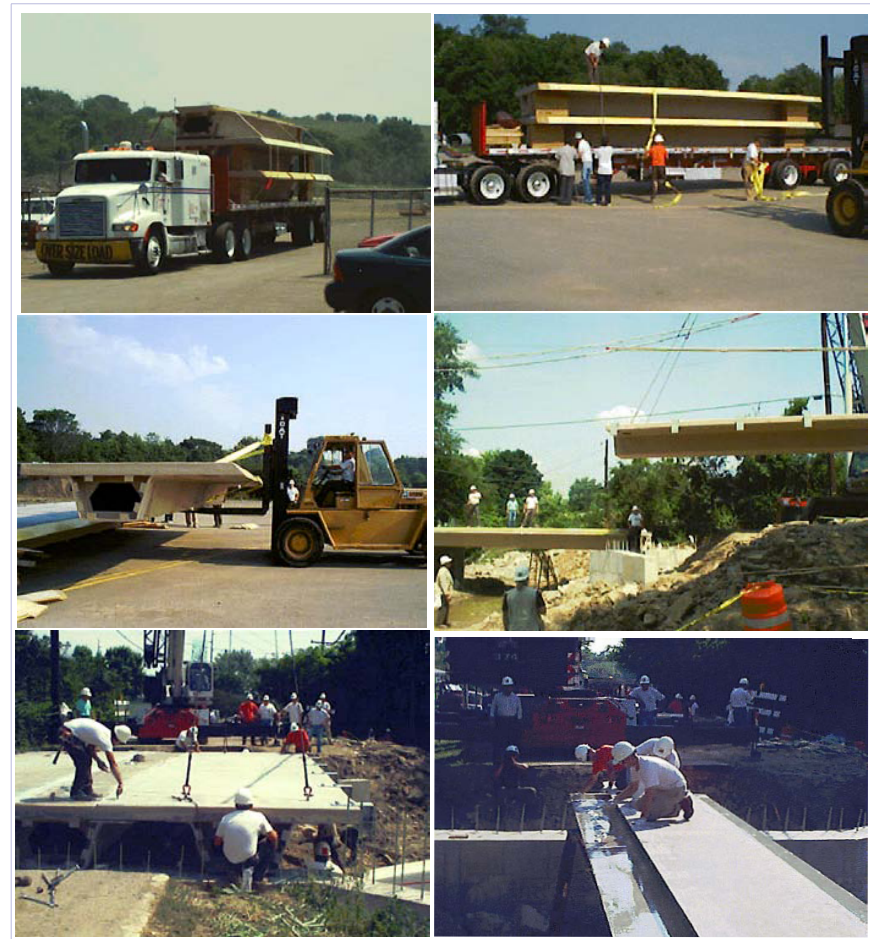

Figure 40: Construction stages of the smith road bridge all-composites bridge, Ohio, USA.

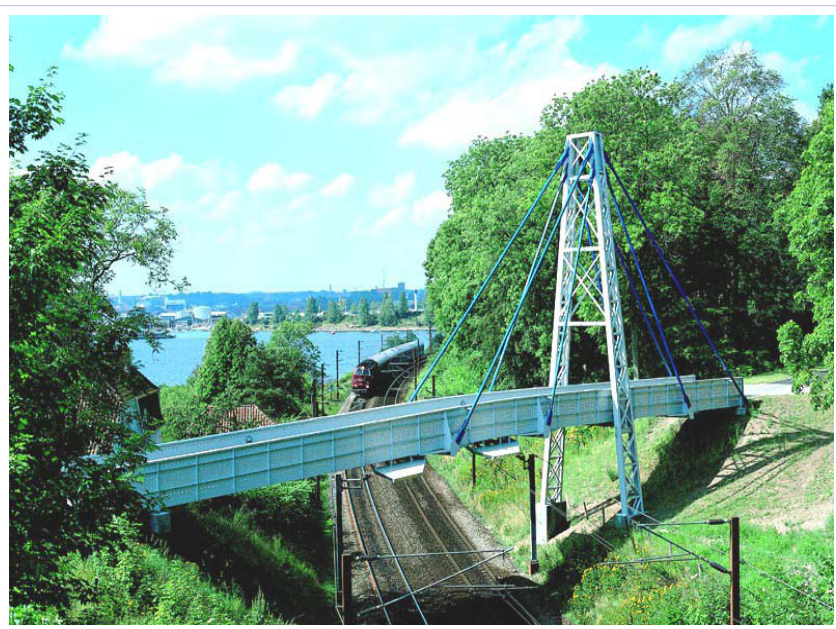

Figure 41: The fiberline all-composite cable-stayed in Denmark. 


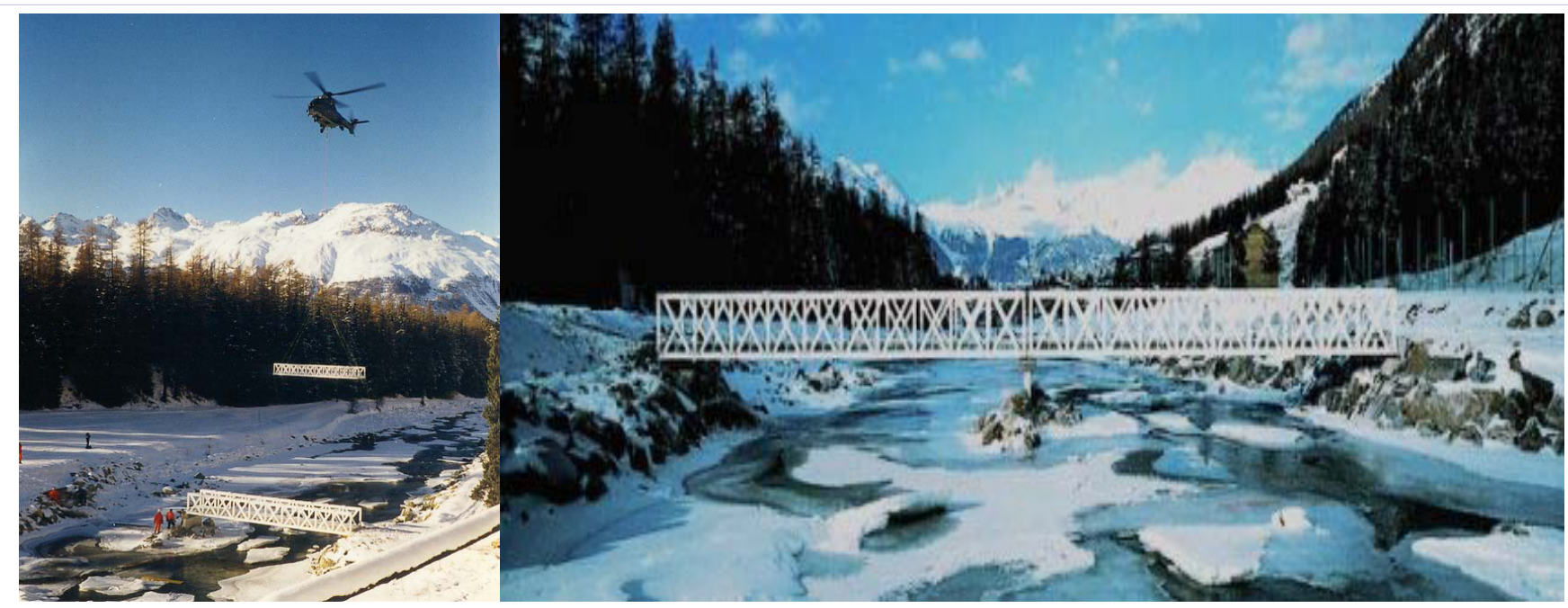

Figure 42: Transportation and construction of pontresina bridge, Switzerland.

\section{United States of America (USA)}

The American Society of Civil Engineers (ASCE), American Concrete Institute (ACI), American Association of State Highway and Transportation Officials (AASHTO), and the International Code Council (ICC), have been the leading organizations in USA in developing codes, specifications, design guides and national standards in the area of composites for civil infrastructure applications. The following paragraphs describe the efforts of each organization.

The American Society of Civil Engineers (ASCE): Since 1960's, the ASCE has been involved in developing several engineering documents dealing with both unreinforced and fiber reinforced polymers (FRP) materials and systems. In 1984 [51], the ASCE Structural Plastics Design Manual (SPDM) was published (1984) by the Plastic Research Council of the Materials Division of ASCE. Starting late 1980's, as the demand and the acceptance of FRP materials increased, the ASCE recognized the need for more developments in this field. Jointly, with the Society of Plastics Industry (SPI), a long-rang, multi-phase program was established in early 1990's. The ultimate goal of this joint program is to develop accepted standards for structural design, fabrication and erection of FRP composite systems. In 1995, the Pultrusion Industry Council (PIC) of SPI sponsored the first phase of this program to develop a design draft standard or a "prestandard" document with a view to process the prestandard upon completion as an ASCE national consensus standard in accordance with the rules of the American National Standard Institute (ANSI). In late 1995, ASCE awarded Phase I of this project to Chambers Engineering, p.c. (as the General Contractor) and the first author (as the Subcontractor) to undertake a oneyear startup and planning phase of the multi-phase standard program. The scope of work of Phase I was to i) Survey and evaluate existing design and martial information. This task included researching both published and unpublished technical literature, government and university reports, performance data, standards and specification documents (ASTM, ACI, ASCE, JSCE,
Eurocode, Canada,...), manufacturer's materials data, and current practice relative to the use of FRP composites, ii) development of a computerized database containing the relevant and evaluated useful technical information, iii) using this database, identify gaps in knowledge that may impede promulgation of the standard, and finally, iv) developing the prestandard outline through defining the approach including recommended design philosophy and relationship of the ASCE design standard with other martial or industry standards such as AASHTO, ASTM, ISO, ICC. The second phase of this program is in progress that aims at establishing a Standard LRFD Design of Pultruded Fiber reinforced Polymer (FRP) Structures. Lately, the American Society of Civil Engineers (ASCE) has published a Structural Design Manual (MOP 102) on FRP composite connections (www.asce.org). The manual consists of ten chapters covering a wide range of design topics related to joining PFRP frame structures (Mosallam, 2011).

American Concrete Institute (ACI): In 1993, the American Concrete Institute (ACI) realized the potential of the polymer composites in concrete applications. For that reason, a new committee (ACI 440) was formed to answer the needs of this new industry and to provide guidelines for design, specifications, and applications of polymer composites as external and internal reinforcement systems. Due to the rapid increase of new polymer composite products and applications, the ACI 440 committee was divided to several subcommittees focusing on different design and application aspects of polymer composites in concrete applications. This includes subcommittees on internal reinforcements (FRP rebars), FRP Prestressing, FRP external repair, education, and others. One of the active subcommittees is the ACI-440 subcommittee on FRP External Reinforcements (ACI 440F). The information presented in ACI 440 documents will assist the structural engineer in properly selecting and designing an optimum and reliable FRP system. The documents also describe conditions where FRP strengthening is beneficial and where its use may be limited. The following are the current ACI 440 publications that can be obtained from the American Concrete Institute web site: www.concrete.org 
- ACI 440R-07 "Report on Fiber-Reinforced Polymer (FRP) Reinforcement for Concrete Structures," ACI Committee 440, American Concrete Institute, Farmington Hills, Mich., (2007), 100p.

- ACI 440.1R-06 "Guide for the Design and Construction of Structural Concrete Reinforced with FRP Bars," ACI Committee 440, American Concrete Institute, Farmington Hills, Mich., (2006), 44p.

- ACI 440.5-08 "Specification for Construction with FiberReinforced Polymer Reinforcing Bars," ACI Committee 440, American Concrete Institute, Farmington Hills, Mich. (2008), $5 p$.

- ACI 440.6-08 "Specification for Carbon and Glass Fiber-Reinforced Polymer Bar Materials for Concrete Reinforcement," ACI Committee 440, American Concrete Institute, Farmington Hills, Mich., (2008), 6p.

- ACI 440.3R-04 "Guide for Test Methods for Fiber Reinforced Polymers (FRP) for Reinforcing and Strengthening Concrete Structures," ACI Committee 440, American Concrete Institute, Farmington Hills, Mich., (2004), 40p.

- ACI 440.2R-08 "Guide for the Design and Construction of Externally Bonded FRP Systems for Strengthening Concrete Structures," ACI Committee 440, American Concrete Institute, Farmington Hills, Mich., (2008), 76p.

- ACI 440.7R-10 "Guide for the Design and Construction of Externally Bonded FRP Systems for Strengthening Unreinforced Masonry Structures" ACI Committee 440, American Concrete Institute, Farmington Hills, Mich., (2010), 46p.

- ACI 440.4R-04 "Prestressing Concrete Structures with FRP Tendons, " ACI Committee 440, American Concrete Institute, Farmington Hills, Mich., (2004), 35p.

International Code Council (ICC): In 1997, the International Code Council, ICC of USA (formerly called International Conference for Building Officials, ICBO) Evaluation Service (ES) produced two acceptance criteria related to repair and rehabilitation of reinforced concrete and masonry structures; namely AC125 and AC 178 that are available at the ICC-ES website (icc-es.org) Unlike the ACI current proposed document, the AC125 focused more on applications related to seismic design.

American Association of State Highway and Transportation Officials (AASHTO): For pedestrian bridge applications, the American Association of State Highway and Transportation Officials has published a guide specifications for designing such bridges 2008. In 2009, AASHTO published an LRFD Bridge design guide specifications for GFRP-reinforced concrete bridge decks and traffic railings. Copies of these documents can be obtained at the AASHTO website: www.transportation.org

\section{Japan}

In Japan, the Research Committee on Continuous Fiber Reinforcing Materials published a recommendation for design and construction of concrete structures using continuous fiber reinforcing materials (1997) [52]. Sonobe Y, et al. [53] provided an English translation of the Japanese Design Guidelines of FRP Reinforced Concrete Building Structures. In 1999, the, Japan Building Disaster Prevention Association (JBDPA) [54] published a design and construction guidelines for the use of FRP composites in seismic retrofitting of existing RC Buildings. Also, the Japanese Society of Civil Engineers (JSCE) established a subcommittee on FRP Bridges was and has published in 2004 [55] a technical report titled "FRP bridges - technologies and their future". Some of these documents are accessible to public at:

http://www.jsce.or.jp/committee/concrete/e/newsletter/ newsletter01/recommendation/FRP-sheet/document.htm

\section{Canada}

In Canada, major efforts in establishing design and specifications for FRP composites in construction have been have been accomplished. The Canadian Standards Association has taken the lead in this effort by developing two documents focusing on FRP composites; namely (i) Design and Construction of Building Components with Fibre-Reinforced Polymers (2007) [56], and (ii) Specification for Fibre-Reinforced Polymers (2010) [57]. For bridge applications, design information on composites was included in the Canadian Highway Bridge Design Code (2006) [58]. These documents can be obtained through the Canadian Standards Association web site: http://shop.csa.ca/. Several documents were also developed by the ISIS Canada Research Network (ISIS). The following are some of the ISIS published design related publications that can be obtained from ISIS web site: http://www.isiscanada.com/publications/design-manuals/

- ISIS Design Manual No. 2 - Guidelines for Structural Health Monitoring, ISIS Canada

- ISIS Design Manual No. 3 - Reinforcing Concrete Structures with Fibre Reinforced Polymers (FRPS), ISIS Canada

- $\quad$ ISIS Design Manual No. 5 - Prestressing Concrete Structures with FRPs, ISIS Canada

- ISIS Product Certification - Specifications for FRP Product Certification of FRPs as Internal Reinforcement in Concrete Structures, ISIS Canada

- ISIS Durability Monograph - Durability of Fibre Reinforced Polymers in Civil Infrastructure, ISIS Canada

\section{Europe}

In Europe, several organizations have been working on developing standard and technical documents related to FRP composites in construction applications. One of the active organization is fib (fédération internationale du béton or the International Federation for Structural Concrete). Two bulletins (Bulletin 14 and Bulletin 35) were published by fib in 2001 [59] and 2006 [60]. These documents can be obtained from the fib web site: http://www.fib-international.org/publications/fib

A technical document on design and construction of structures made of thin FRP pultruded elements was published in 2002 by 
the European Committee for Standardization (CEN), Brussels, Belgium. A copy of this document can be found at: http://www. cnr.it/documenti/norme/IstruzioniCNR_DT205_2007_eng.pdf

The EUROCOMP Design Code and Handbook was developed and published (Clark, ed. 1996). In Germany, the German Institute for Building Technology developed guidelines for the use of FRP composites for strengthening RC structures that was published in 1998. The UK Concrete Society published guidelines for design and inspection of RC members strengthened with FRP composites [61,62].

\section{Middle East \& North Africa}

The first design code for FRP composites in Strengthening and Repair applications was developed few years ago in Egypt. The code is published by the Housing and Buildings National Research Center (HBRC). Copies of this code can be obtained through HBRC website: http://www.hbrc.edu.eg/en/Home.html

\section{Australia}

Funded by the Australian Federal Government, the Queensland State Government, with additional support from a range of industry stakeholders, an initiative to establish a Fibre Composites Design and Development (FCDD) program was initiated with an ultimate goal of developing a design code of practice for FRP composites. Similar to the ICC-ES certification program in USA, another initiative to develop a National Constituent Certification Scheme (NCSS) to provide a mechanism for evaluating and accepting different types of FRP composites systems for infrastructure applications.

\section{International Organization for Standardization (ISO)}

Three ISO documents were published related to FRP composites:

- ISO/DIS 14484, Performance Guidelines for Design of Concrete Structures using Fibre-reinforced Polymer Materials,

- ISO 10406-1 Fibre-reinforced polymer (FRP) reinforcement of concrete - Test methods - Part 1: FRP bars and grids.

- ISO 10406-2 Fibre-reinforced polymer (FRP) reinforcement of concrete - Test methods - Part 2: FRP sheets.

These international standard documents are available at the ISO website: http://www.iso.org

\section{References}

1. ASCE's (2013) Report Card on America's Infrastructure, American Society of Civil Engineers (ASCE), Reston, Virginia, USA.

2. Mosallam AS (2002) Chapter 45: Chapter on composites in construction Materials Selection Handbook. John Wiley Publishing, NY, USA, p. 53.

3. El-Mikawi M, Mosallam AS (1996) A Methodology for evaluation of the use of advanced composites in structural civil engineering applications. Composites Part B: Engineering 27(3-4): 203-215.

4. Youssef MN, Feng MQ, Mosallam AS (2007) Stress-strain model for concrete confined by FRP composites. Composites Part B: Engineering 38(5-6): 614-628.
5. Mosallam AS (2000) Seismic retrofitting of steel beam-to-column joints with polymer composites \& steel stiffeners. Proc., Composites in the Transportation Industry, Sydney, Australia, pp. 198-203.

6. Liu C (2006) Seismic behavior of beam-column joint subassemblies reinforced with steel fibers. MSCE thesis, University of Canterbury, New Zealand.

7. Tsonos AG (2008) Effectiveness of CFRP-jackets and RC-jackets in post-earthquake and pre earthquake retrofitting of beam column subassemblages. Journal of Engineering Structures 30(3): 777-793.

8. Supaviriyakit T, Pimanmas A (2007) Comparative performance of a substandard beam-column joint with and without initial bond between beam bars and concrete in the joint core. Thammasat Int J Sc Tech 12(1): 42-51.

9. Pantelides C, Okahashi Y, Reaveley L (2008) Seismic rehabilitation of reinforced concrete frame interior beam-column joints with FRP composites. Journal of Composites for Construction 12(4): 435-445.

10. Mosallam AS (2009) Structural upgrade of reinforced concrete column-tie beam assembly using FRP composites. American Concrete Institute SP-258: 57-68.

11. Hwang SJ, Tu YS, Yeh YH, Chiou TC (2004) Reinforced concrete partition walls retrofitted with carbon fiber reinforced polymer. 2004 ANCER Annual Meeting: Networking of Young Earthquake Engineering Researchers and Professionals, ANCER.

12. Khalil A, Ghobarah A (2005) Behaviour of rehabilitated structural walls. Journal of Earthquake Engineering 9(3): 371-391.

13. Meftah SA, Yeghnem R, Tounsi A, Adda Bedia EA (2007) Seismic behavior of RC coupled shear walls repaired with CFRP laminates having variable fibers spacing. J Construction and Building Materials 21(8): 1661-1671.

14. Kitano A, Joh O, Goto Y (2004) Experimental study on the strengthening and repair of $\mathrm{R} / \mathrm{C}$ wall-frame structures with an opening by $\mathrm{CF}$-sheets or CF-grids. Proc., $2^{\text {nd }}$ International Conference on FRP Composites in Civil Engineering - CICE 2004. IIFC, Adelaide, Australia.

15. Choi CS, Choi YC, Choi HK, Lee MS (2007) Retrofit of artificially perforated shear wall in existing dominant wall structure. Key Engineering Materials 348-349: 917-920.

16. Mosalam K, Mosallam AS (2001) Nonlinear transient analysis of reinforced concrete slabs subjected to blast loading and retrofitted with CFRP composites. Composites Part B: Engineering 32(8): 623636.

17. Mosallam AS, Mosalam KM (2003) Strengthening of unreinforced concrete slabs with polymer composite laminates. Construction and Building Materials 17(1): 43-54.

18. ACI Committee 440 (2008) Guide for the design and construction of externally bonded FRP systems for strengthening concrete structures, ACI 440.2R-08, American Concrete Institute, Farmington Hills, MI, USA.

19. Mosallam AS, Banerjee S (2011) Enhancement in in-plane shear capacity of unreinforced masonry (URM) walls strengthened with fiber reinforced polymer composites. Composites Part B: Engineering 42(6): 1657-1670.

20. Kim JJ, Noh HC, Taha MMR, Mosallam A (2013) Design limits for RC slabs strengthened with hybrid FRP-HPC retrofit system. Composites Part B: Engineering 51: 19-27.

21. Qiao P, Yang M, Mosallam AS (2004) Impact analysis of I-Lam sandwich system for over-height collision protection of highway 
bridges. Engineering Structures 26: 1003-1012.

22. Mosallam AS (1999) Making the connections. Civ Eng Mag 69(4): 56 59.

23. Mosallam AS (2000) Strength and ductility of reinforced concrete moment frame connections strengthened with quasi-isotropic laminates. Composites Part B: Engineering 31(6-7): 481-497.

24. Sen R, Liby L (1994) Repair of steel composite bridge sections using carbon fiber reinforced plastic laminates-Restraint effect of bearingsPhase II. Final Report, Florida Dept. of Transportation, Tallahassee, FL, USA.

25. Garden HN, Shahidi EG (2002) Steel building rehabilitation using composites. Proc. Advanced Polymeric Composites for Structural Applications in Construction, ACIC '02, Southampton, UK, pp. 457-465.

26. Tavakkolizadeh M, Saadatmanesh H (2003) Repair of damaged steelconcrete composite girders using carbon fiber-reinforced polymer sheets. J Compos Constr 7: 311-322.

27. Photiou N (2004) Strengthening of an artificially degraded steel beam utilizing a carbon/glass composite system. Proc., ACIC'2004 Conference, University of Surrey, UK, pp. 274-283.

28.Schnerch D, Lanier B, Rizkalla S, Nakagoshi A (2004) Flexural strengthening of steel bridges and towers using high modulus CFRP materials. Proceedings $2^{\text {nd }}$ International Conference on Bridge Maintenance, Safety, and Management (IABMAS '04), Kyoto, Japan.

29. Peiris NA(2011) Steel beams strengthened with ultra high modulus CFRP laminates, Dissertation, Civil Engineering Department, University of Kentucky, 284ps.

30. Zhao XL, Zhang L (2007) State-of-the-art review on FRP strengthened steel structures. Engineering Structures 29: 1808-1823.

31. Mosallam A (2007) Structural evaluation and construction of FRP composites strengthening systems for the sauvie island bridge. J Compos Constr 11(2): 236-249.

32. Polyzois D, Kell JA (2007) Repair and rehabilitation of wood utility poles with fibre-reinforced polymers. Canadian Journal of Civil Engineering 34(1): 116-119.

33. Lopez-Anido R, Michael A, Sandford TC (2003) Experimental characterization of FRP composite-wood pile structural response by bending tests. Marine Structures 16(4): 257-274.

34. Tingley D (1999) Reinforced plastic computability with wood composites. Proceedings, $5^{\text {th }}$ ASCE Materials Engineering Congress, pp. 108-115.

35. Gilfillan JR, Gilbert SG, Patrick GRH (2003) The use of FRP composites in enhancing the structural behavior of timber beams. Journal of Reinforced Plastics \& Composites 22(15): 1373-1388.

36. Triantafillou $T$ (1997) Shear reinforcement of wood using FRP materials. Journal of Materials in Civil Engineering 9(2): 65-69.

37. Hess R (2007) Impacts of a M7.8 Southern San Andreas earthquake on unreinforced masonry (URM) buildings. Prepared for United States Geological Survey, Pasadena and California Geological Survey, Sacramento under contract to SPA Risk LLC, Denver, Colorado, USA.

38. Holberg M, Hamilton R (2002) Strengthening URM with GFRP composites and ductile connections. Earthquake Spectra 18(1): 63-84.

39. Mosallam AS (2007) Out-of-plane flexural behavior of unreinforced red brick walls strengthened with FRP composites. Composites Part B: Engineering 38(5-6): 559-574.
40.ACI 440.7R-10 (2010) Guide for the design and construction of externally bonded FRP system for strengthening unreinforced masonry structures. Reported by ACI Committee 440, Farmington Hills, MI, USA.

41. Petersen RB, Masia MJ, Seracino R (2010) In-plane shear behavior of masonry panels strengthened with NSM CFRP strips II: finite element model. J Compos Constr 14(6): 764-774.

42. Haroun MA, Mosallam AS, Allam KH (2005) Cyclic in-plane shear of concrete masonry walls strengthened by FRP laminates. ACI Special Publication, 230(19): 327-340.

43. Haroun MA, Mosallam AS, Feng MQ, Elsanadedy HM (2003) Experimental investigation of seismic repair and retrofit of bridge columns by composite jackets. Journal of Reinforced Plastics and Composites 22(14): 1243-1268.

44. Mosallam AS, Pul S, Elsadek A (2010a) Rotational behavior of webflange junctions of open-web pultruded composites. Proceedings of the $9^{\text {th }}$ International Congress on Advances in Civil Engineering (ACE2010-SEE-146), Turkey.

45. Mosallam AS, Elsadek A, Pul S (2010b) Pull-out behavior of web-flange junctions of open-web pultruded composites. Proceedings of the $9^{\text {th }}$ International Congress on Advances in Civil Engineering (ACE2010SEE-146), Turkey.

46. Feo L, Mosallam AS, Pennaa R (2013) Mechanical behavior of webflange junctions of thin-walled pultruded i-profiles: an experimental and numerical evaluation. Composites Part B: Engineering 48: 18-39.

47. Mosallam AS (2011) Design for FRP composite connections. ASCE Manuals and Reports on Engineering Practice MOP\#102, American Society of Civil Engineers (ASCE), Reston, Virginia, USA.

48.FHWA (2013) Composite bridge decking: final project report, Publication No. FHWA-HIF-13-029, 88.

49. Alagusundaramoorthy P, Harik IE, Choo CC (2006) Structural behavior of FRP composite bridge deck panels. Journal of Bridge Engineering 11(4): 384-393.

50. Aashto (2009) LRFD Bridge design guide specifications for GFRPreinforced concrete bridge decks and traffic railings. American Association of State Highway and Transportation Officials, Washington DC 68, USA.

51. ASCE (1984) Structural plastics design manual. ASCE Manual No. 63, American Society of Civil Engineers, Reston, VA, USA.

52. Japanese Society of Civil Engineers (JSCE) (1997) Recommendation for design and construction of concrete structures using continuous fiber reinforcing materials. Research Committee on Continuous Fiber Reinforcing Materials, Concrete Engineering Series, No.23, Tokyo, Japan.

53. Sonobe Y, Fukuyama H, Okamoto T, Kan N, Kimura K, et al. (1997) Design guidelines of FRP reinforced concrete building structures. J Compos Const 1(3): 90-115.

54.JBDPA, Japan Building Disaster Prevention Association (1999). Seismic Retrofitting Design and Construction Guidelines for Existing Reinforced Concrete (RC) Buildings with FRP Materials, Japan.

55. Japanese Society of Civil Engineers, JSCE (2004). FRP Bridges Technologies and their Future, Subcommittee on FRP Bridges, Committee of Structural Engineering, Structural Engineering Series, JSCE, Tokyo, Japan.

56.CAN/CSA-S806-02 (2007) Design and Construction of Building Components with Fibre-Reinforced Polymers. Canadian Standards 
Association, Toronto, Ontario, Canada, p. 218.

57.CAN/CSA-S807-10 (2010) Specification for Fibre-Reinforced Polymers. Canadian Standards Association, Toronto, Ontario, Canada, p. 44.

58. CAN/CSA-S6-06 (2006) Canadian Highway Bridge Design Code. Canadian Standards Association, Toronto, Ontario, Canada, pp. 1078.

59. Fib Bulletin No. 14 (2001) Externally bonded FRP reinforcement for RC structures. pp. 138, ISBN 978-2-88394-054-3.
60. Fib Bulletin No. 35 (2006) Retrofitting of concrete structures by externally bonded FRPs, with emphasis on seismic applications. pp. 220, ISBN 978-2-88394-075-8.

61.TR55 (2004) Design guidance for strengthening concrete structures using fiber composite materials: a review. Concrete Society, UK.

62. TR57 (2003) Strengthening concrete structures with fiber composite materials: acceptance, inspection and monitoring, Concrete Society, UK. 